INSTITUTO DE PESQUISAS ENERGÉTICAS E NUCLEARES

Autarquia associada à Universidade de São Paulo

\title{
AVALIAÇÃO DO PROCESSO DE PRODUÇÃO - ESTUDO DIMENSIONAL DE PEÇA SINTERIZADA
}

\author{
Benjamin Teixeira Dourado
}

Dissertação apresentada como parte dos requisitos para a obtenção do Grau de Mestre em Ciências na Área de Tecnologia Nuclear Materiais.

Orientador: Dr. Jesualdo Luiz Rossi

São Paulo 2008 
À minha amada esposa Alessandra e meus filhos: Carolina, Arthur, Pedro e Otávio 


\section{AGRADECIMENTOS}

Ao Instituto de Pesquisas Energéticas e Nucleares pela oportunidade de realizar este trabalho.

Ao Dr. Jesualdo Luiz Rossi pelo acolhimento nesse instituto, pelas orientações e, principalmente pela amizade.

Ao Dr. João Vicente Zampieron, pelas suas palavras amigas, fundamentais na superação dos obstáculos, pessoa presente desde o início dos trabalhos.

Ao Dr. Lúcio Salgado pelas valiosas sugestões que enriquecem esta pesquisa. A BRATS pela valiosa colaboração na prensagem das amostras.

Ao Centro Universitário Sant'Anna pelo apoio e compreensão no tempo disponibilizado a das pesquisas

Aos amigos Dr. Sidnei José Buso, Dr. Américo de Almeida Filho e MSc. Jair dos Santos Jr., pelo incentivo.

Um agradecimento especial a Dr. Américo de Almeida Filho pelas sugestões e discussões que em muito contribuíram para a conclusão deste

A professora Isis Maitê Fullas Aguiar que dispôs de tempo e paciência apoiando com seu conhecimento na língua inglesa.

Ao Sr. Washington Jorge Natale, reponsável pelo laboratório de ciências do Centro Universitário Santanna que permitiu e auxiliou nas medições das peças.

A Metalpó pelo apoio material no fornecimento de pó de cobre fundamental na elaboração da matéria-prima.

Aos colegas do CCTM - Centro de Ciência e Tecnologia de Materiais pelo companheirismo e apoio nos momentos difíceis dessa dissertação. 


\section{AVALIAÇÃO DO PROCESSO DE PRODUÇÃO - ESTUDO DIMENSIONAL DE PEÇA SINTERIZADA}

\section{Benjamin Teixeira Dourado}

\section{RESUMO}

A presente pesquisa é proveniente da necessidade de conhecer os mecanismos de controle de peças sinterizadas, tendo como objetivo a melhoria da produção. Esse gerenciamento representa uma grande influência no preço da tecnologia. Mais especificamente o estudo de caso é relacionado ao controle dimensional de um calço sinterizado. Essa peça de geometria simples, um disco, deve ter o seu diâmetro e acima de tudo a sua altura controlados. O diâmetro é controlado pelas dimensões estabelecidas, as características da mistura de pós e o forno de sinterização. Uma vez esses parâmetros estejam corretamente estabelecidos, o diâmetro do calço pode não variar substancialmente. Entretanto, o controle

de altura da peça é um passo crítico. A precisão requerida pode ser na ordem de 0.05 $\mathrm{mm}$ para cada categoria que os calços são divididos, o que é difícil de ser atingido em grande números em baixa dispersão. Sempre haverá uma variação em torno de um valor significativo. Nesse estudo, utilizando o processo de controle estatístico como um instrumento de decisão é encontrada sob qual condição a produção é melhor estabelecida. Além disso, o estudo permite o estabelecimento de quantas partes serão fabricadas para a obtenção de uma altura particular e quantas partes serão reclassificadas. Toda essa informação implica diretamente no controle de custo de produção. 


\title{
EVALUATION OF THE PRODUCTION PROCESS - DIMENTIONAL STUDY OF SINTERED PART
}

\section{Benjamin Teixeira Dourado}

\begin{abstract}
ABSTRAT
The proposition for this work comes to the necessity of the knowledge of mechanisms controls for sintered parts, aiming the improvement of the production. This management means a great influence in the technology price. More specifically the case study is related to the dimensional control of a sintered shim. This part of simple geometry, i.e., a disk, has to have its diameter and above of all the height accurately controlled. The diameter is controlled by the die set dimensions, powders mixture characteristics and sintering furnaces. Once these parameters are correctly set, the shim diameter may not vary substantially. However, the part height control is a critical step. The required precision may be in the order of $0.05 \mathrm{~mm}$ for each class that are divided the shims, which is difficult to be attained in large numbers at small dispersion. There will be always a variation around a mean value. In this study, using the statistical process control as a decision-taking instrument it is found under which condition the best yield is set. Moreover, the study allows the establishment of how many parts are to be fabricated for the obtention of a particular height class and how many parts will be reclassified. All this information directly implicate in production cost control.
\end{abstract}




\section{SUMÁRIO}

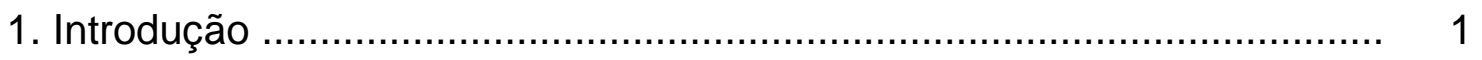

2. Objeto de estudo................................................................. 2

3. Revisão de literatura.............................................................. 3

3.1. Metalurgia do pó.............................................................. 3

3.1.1. Obtenção de pós de ferro..................................................... 4

3.1.2. A compactação dos pós .................................................... 5

3.2. A sinterização ................................................................... 5

3.3. Aspectos gerais da produção ................................................ 9

3.3.1. A produção como um sistema ............................................. 9

3.3.2. A produção como função organizacional .................................. 10

3.3.2.1. A tomada de decisão .................................................. 10

3.3.2.2. A modelagem de dados .................................................... 11

3.3.2.3. A solução do modelo ..................................................... 13

3.3.3.4. Relatório de resultados ................................................. 13

3.4. Controle estatístico de processos ......................................... 13

3.4.1. Definições .................................................................... 13

3.4.2. O controle estatístico de processo (CEP).................................. 15

3.4.3. Capabilidade do processo ............................................... 23

3.4.4. Outras ferramentas do CEP ................................................. 26

4. Materiais e métodos .............................................................. 27

4.1. Materiais ......................................................................... 27

4.2. Caracterização dos pós .......................................................... 28

4.3. Análise da compressibilidade ................................................ 29

4.4. O processo ................................................................ 30

4.5. O tratamento estatístico ...................................................... 31

4.5.1. Montagem dos gráficos de controle .................................... 32

5. Resultados e discussão

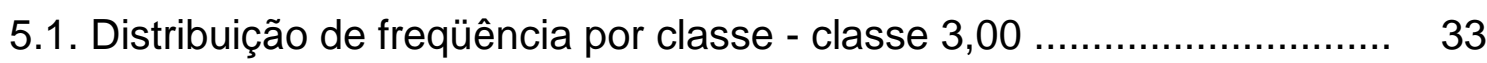

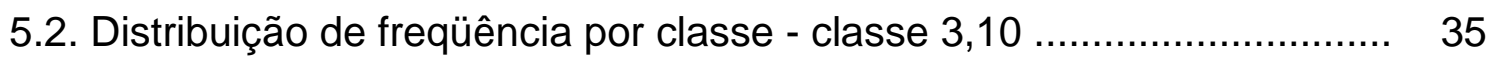

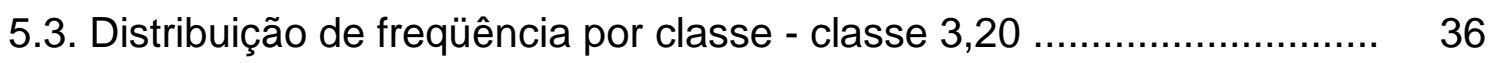

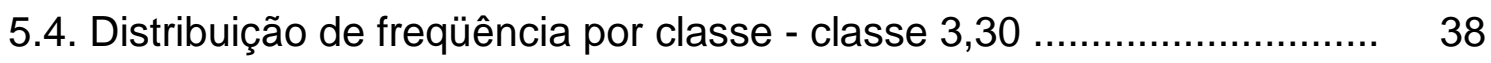

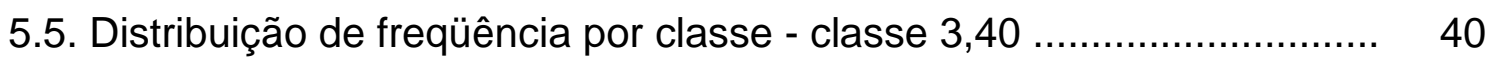

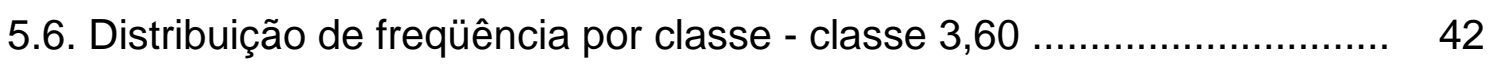

5.7. Exame da capacidade do processo ....................................... 44 


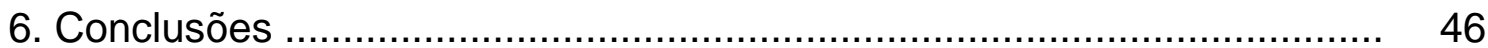

Referências bibliográficas ............................................................. 47

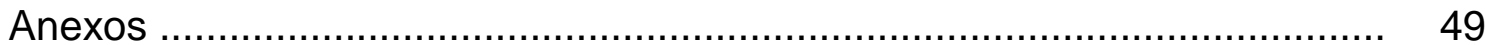




\section{LISTA DE FIGURAS}

Calço conforme compactado. a) Vista de planta e b) vista de 2

Figura 1 topo. O diâmetro final da peça é dado pela cavidade da matriz, da pressão de compactação, do tipo de pó a ser usado e da condições de sinterização

Figura 2 Representação da área de ciência e engenharia de materiais por 8 um tetraedro

Figura 3 Elementos do sistema de produção .......................................... 10

Figura 4 Abordagem a um problema de decisão ........................................ 12

Figura 5 Diagrama de Ishikawa ........................................................... 14

Figura $6 \quad$ Gráfico de controle de Shewhart ............................................. 18

Figura $7 \quad$ Processo sob controle estatístico............................................ 19

Figura $8 \quad$ Processo fora de controle estatístico ........................................... 20

Figura 9 Exemplo de tendência em gráfico de controle ............................. 20

Figura 10 Exemplo de estratificação ou falta de variabilidade ..................... 21

Figura 11 Exemplo de seqüência ...................................................... 21

Figura 12 Exemplo de periodicidade em gráfico de controle ........................ 22

Figura 13 Exemplo de deslocamento em gráfico de controle ....................... 22

Figura 14 Fluxograma do controle estatístico do processo............................. 23

Figura 15 Fluxo do processo de metalurgia do pó ....................................... 27

Figura 16 Gráfico de carga $x$ deslocamento obtido na compressibilidade do 29 pó de ferro ASC 100.29

Figura 17 Misturador do tipo $\mathrm{Y}$ utilizado nos experimentos ........................ 30

Figura 18 Prensa hidráulica instrumentada Silme usada na compactação 30 das amostras

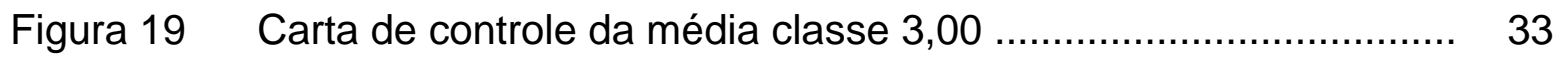

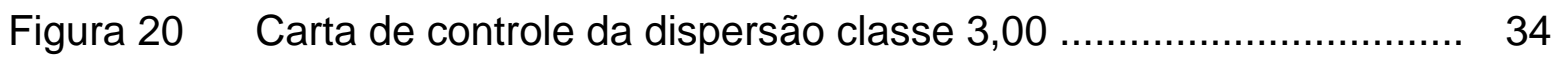

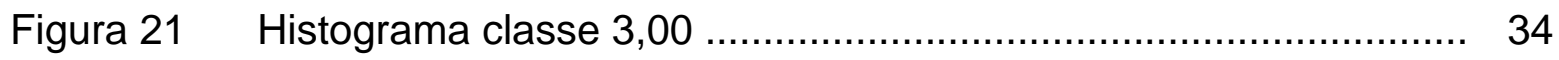

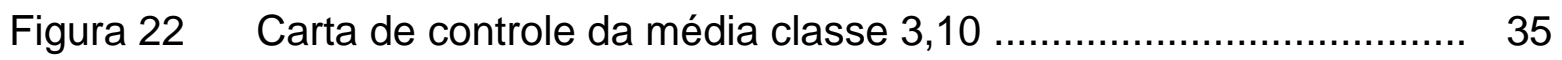

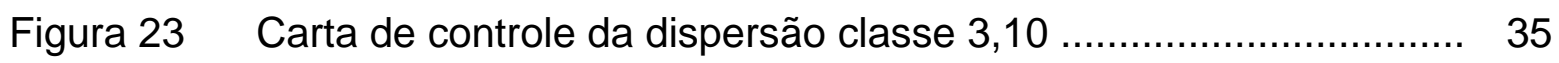

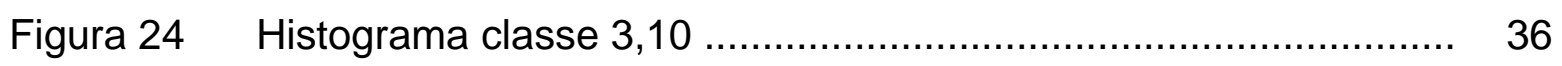

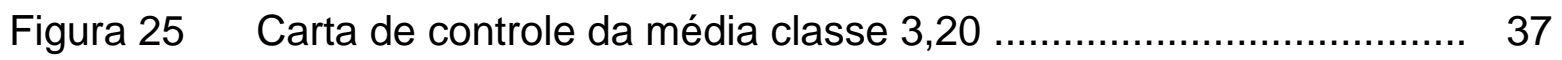

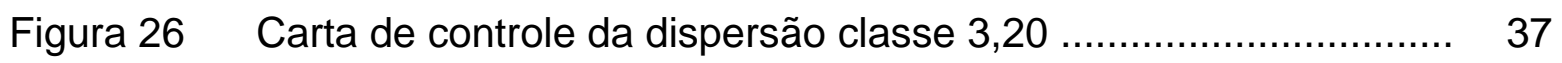

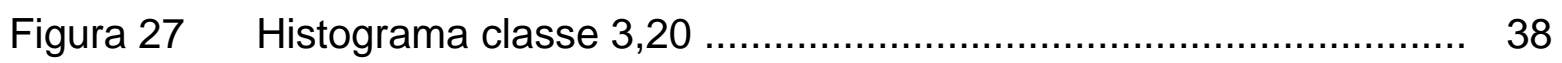

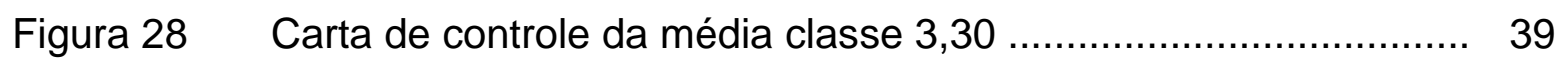

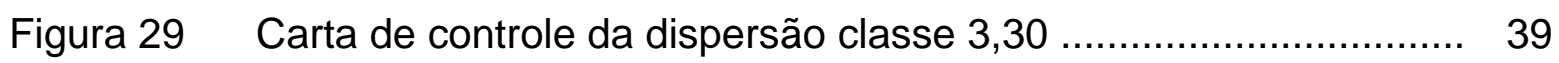

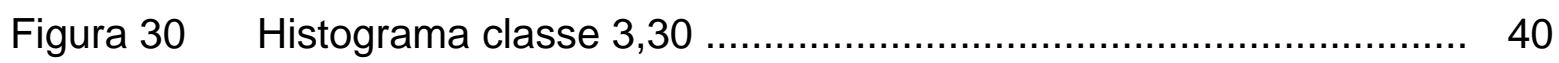




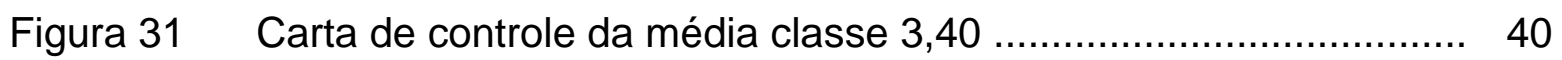

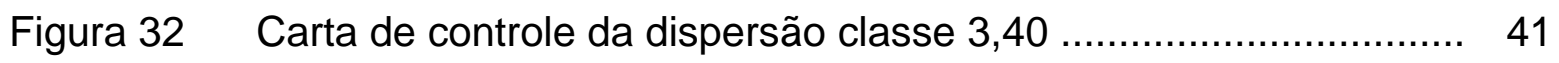

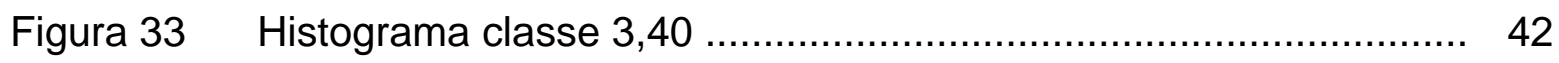

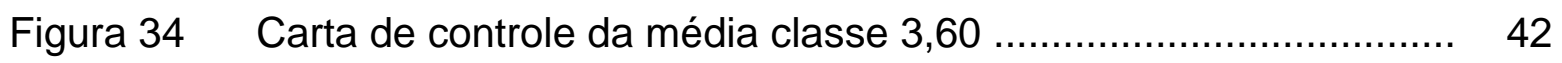

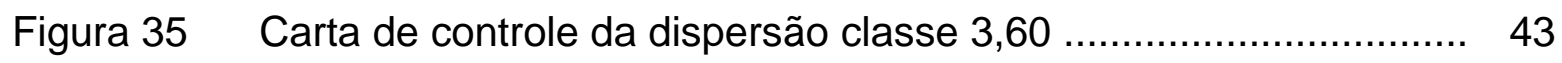

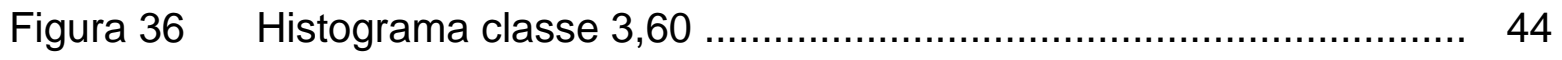




\section{LISTA DE TABELAS}

Tabela 1 Processos de compactação usados na metalurgia do pó ............... 6

Tabela 2 Propriedades físicas do pó de ferro ASC 100.29 ....................... 28

Tabela 3 Composição química do pó de ferro (\% em massa) ASC 100.29 .. 28

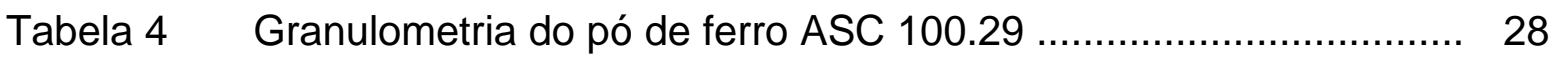

Tabela 5 Análise química e termodinâmica do pó de Grafite - Micrograf 28 9925 MP ML - SC 15 PL

Tabela 6 Analise química do pó grafite - Micrograf 9925 MP ML - SC 1529 PL

Tabela $7 \quad$ Análise física do pó de cobre PAC - D.2200.017 ....................... 29

Tabela 8 Relação da profundidade da cavidade com a altura da peça a 31 verde

Tabela $9 \quad$ Resumo dos dados coletados ............................................... 32

Tabela 10 Distribuição de freqüência por classe 3,00 ................................ 34

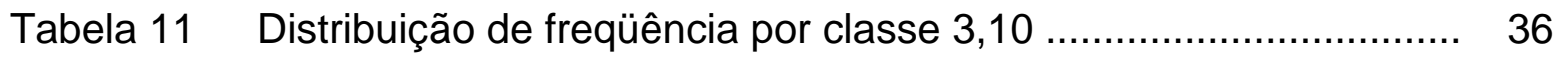

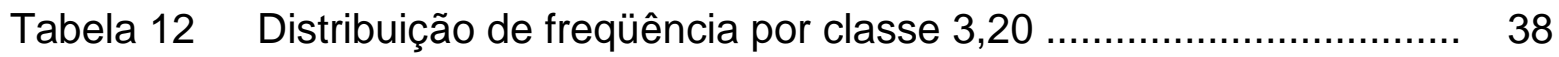

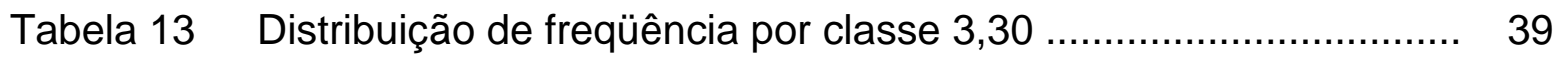

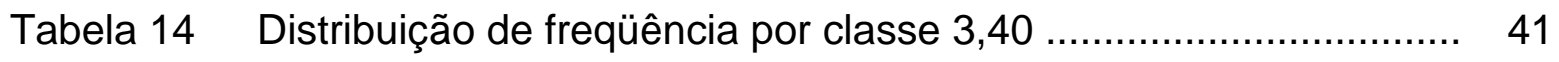

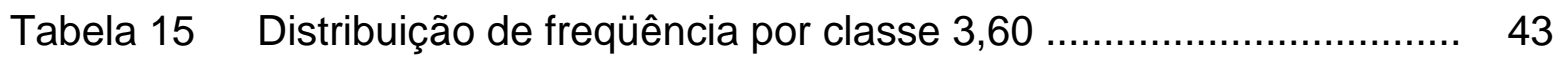

Tabela 16 Índice de capacidade do processo ........................................... 44

Tabela 17 Faixa Característica do Processo ............................................. 45 


\section{INTRODUÇÃO}

Dada a crescente utilização da metalurgia do pó - MP - na confecção de peças utilizadas na indústria automotiva, por apresentar características técnicas favoráveis, são necessários estudos de viabilidade econômica, identificando a metodologia adequada a promoção da eficiência de determinadas particularidades do processo.

O ponto central do presente estudo é a otimização da produção pela análise da variabilidade do processo. A geração de peças fora das especificações, seja pela falha na compactação ou na sinterização, gera retrabalho e custos elevados. As falhas de compactação mais comuns se devem a variações no enchimento da cavidade na matriz.

Outro ponto importante a ressaltar é a questão da competitividade, pois nas ultimas décadas, os consumidores se apresentam cada vez mais seletivo e exigente, exigindo das empresas maior vantagem competitividade, operando com qualidade e baixo custo. Fundamental para a obtenção dessas vantagens é a melhoria dos processos produtivos.

O controle estatístico de processo - CEP - é uma das ferramentas mais clássicas na área de qualidade e com certeza uma das mais comprovadas e empregadas no meio prático. Desde seu surgimento têm sido aplicado aos mais diversos processos, situações e regiões em todo o mundo. Há também um grande conhecimento acumulado sobre sua aplicação, principais benefícios e restrições.

O objetivo do controle estatístico do processo é aprimorar e controlar o processo produtivo por meio da identificação das diferentes fontes de variabilidade do processo. Utilizando conceitos de estatística procura-se separar os efeitos da variabilidade causada pelas chamadas causas comuns, ou seja, àquelas inerentes à natureza do processo produtivo, das causas especiais ou àquelas derivadas da atuação de variáveis específicas e controláveis sobre o processo. A técnica é composta de uma ferramenta principal denominado gráfico de controle que permite identificar se o processo está sob controle estatístico, situação em que atuariam somente causas comuns. 


\section{OBJETO DE ESTUDO}

O presente estudo teve por objetivo de verificar o comportamento do processo de produção dos calços de motor, produzidos por compactação e sinterização. Isto, de tal forma que se estabeleça um instrumento gerencial nesse tipo de produção, otimizado os recursos, indicando a maior produtividade. A referida peça tem uma geometria simples, na forma de um disco, de fácil caracterização com dimensões controladas. As dimensões requeridas para a utilização da peça são: diâmetro $\varnothing 33 \mathrm{~mm}$, admitindo- se uma tolerância de $+0,00$ e $-0,02 \mathrm{~mm}$, vide Fig. 1a) quanto às alturas requeridas, estas partem de $3 \mathrm{~mm}$ até $5 \mathrm{~mm}$, em classes de 0,05 $\mathrm{mm}$ a 0,05 $\mathrm{mm}$, vide Fig. 1b).

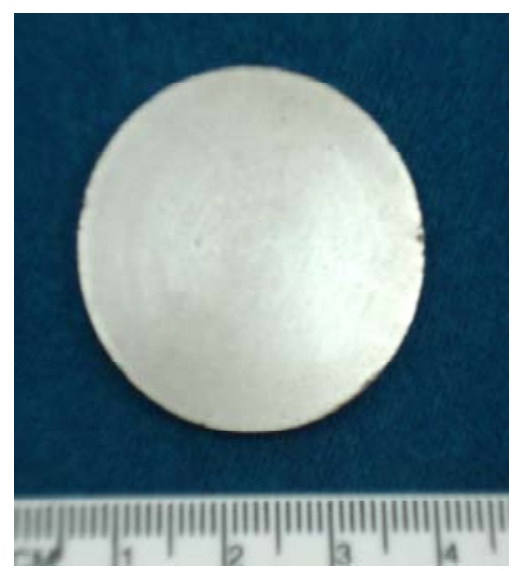

a)

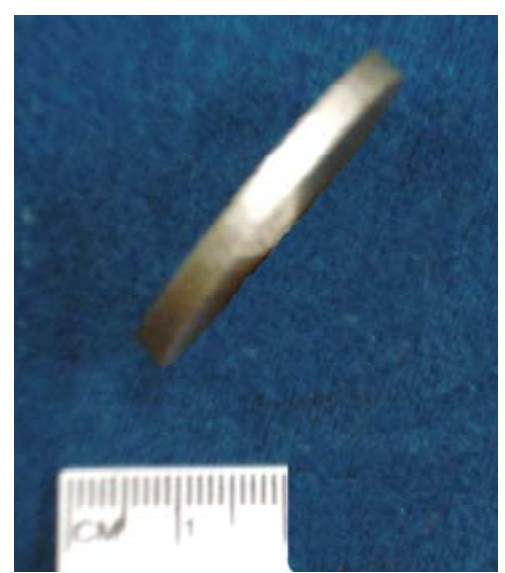

b)

Figura 1. Calço conforme compactado. a) Vista de planta e b) Vista de topo. O diâmetro final da peça é dado pela cavidade da matriz, da pressão de compactação, do tipo de pó a ser usado e das condições de sinterização.

O controle de altura da peça é a etapa crítica do processo. Para determinadas aplicações como o objeto deste estudo, calços para motores a combustão interna, a altura destes é especificada em classes podendo estas ser até dez. Estas classes especificam uma diferença para outra de 0,05 $\mathrm{mm}$. Esta precisão de cinco décimos de milímetro é de difícil obtenção em grandes lotes com pequenas dispersões. Sempre haverá uma variação em torno de um valor médio.

A partir da análise da variabilidade do processo de produção, este estudo objetiva estabelecer as condições para sua produção que proporcione o melhor rendimento em relação a variação de altura, sendo essa a única variável controlada, e permitir que se determine a quantidade de peças que terão de ser produzidas para atender a uma determinada especificação, proporção de sobras de peças fora dos 
limites estabelecidos e, conseqüentemente uma reclassificação das mesmas.

O presente experimento consistiu na produção de 1800 peças distribuídas em 6 lotes de 300 unidades cada, com $\varnothing 15 \mathrm{~mm}$, onde as medidas esperadas em cada lote foram $3,00 \mathrm{~mm} ; 3,10 \mathrm{~mm} ; 3,20 \mathrm{~mm} ; 3,30 \mathrm{~mm} ; 3,40 \mathrm{~mm}$, e $3,60 \mathrm{~mm}$.

\section{REVISÃO DA LITERATURA}

O presente estudo busca analisar um processo de produção à base da tecnologia da metalurgia do pó, utilizando como instrumentos de análise as ferramentas do controle estatístico do processo. Assim, cabe aqui, um breve relato teórico.

\subsection{Metalurgia do pó}

A literatura indica que a fabricação de armas lanças e ferramentas já teriam sido produzidas a partir de aglomerados de ferro a cerca de 6000 anos. Porém, a moderna metalurgia do pó tem início no século XIX. Foi em 1829 que se deu a produção de peças de platina maleável. $\mathrm{O}$ que parece ter sido uma revolução da metalurgia do pó, tendo em vista que em função do alto ponto de fusão do metal, cerca de $1775^{\circ} \mathrm{C}$, este até então não podia ser processado.

No início do século $X X$, foram desenvolvidos processos para obtenção de peças de tungstênio e de molibdênio por sinterização. Mas a produção só se expandiu mesmo após a Segunda Guerra Mundial, para atender à demanda crescente da indústria automobilística [1].

Ao longo dos anos, a metalurgia do pó tem se firmado como uma excelente alternativa aos processos convencionais de produção, pela fundição e conformação mecânica. As vantagens sobre os demais processos têm incentivado a aplicação da metalurgia do pó em diversos setores produtivo, dentre eles destacam-se: maior flexibilidade no projeto de liga, possibilidade de eliminação ou redução das operações de acabamento, economia de matéria-prima, boa precisão dimensional e redução do consumo energético [2]. 
$\mathrm{Na}$ atualidade, são inúmeras as aplicações industriais de peças sinterizadas. O controle exato da composição química desejada do produto final, a redução ou eliminação das operações de usinagem, o bom acabamento superficial, a pureza dos produtos obtidos e a facilidade de automação do processo produtivo são alguns dos motivos que tornaram a metalurgia do pó uma fonte produtora de peças para, praticamente, todos os ramos da indústria [3,4], como o automobilístico, o de informática, o aeroespacial, o de material eletroeletrônico, o de equipamentos e implementos agrícolas, o têxtil e uma infinidade de outros. Segundo a Metal Powder Industries Federation - MPIF, nos Estados Unidos são produzidas, anualmente, mais de um milhão de toneladas de peças sinterizadas, ou seja, um crescimento bastante acentuado, considerando-se que, em meados da década de 1980, essa produção beirava 350 mil toneladas. Dentre as peças típicas destacam-se assentos de válvulas, cames do eixo de comando de válvulas, bielas, peças sincronizadoras, capa de mancal, engrenagens e cubos sincronizadores [2]

Tendo em vista o crescimento constante da metalurgia do pó, para a fabricação de diversas peças, houve uma maior motivação de toda a comunidade científica em aperfeiçoar as técnicas envolvidas no processo, bem como em buscar um melhor aproveitamento da matéria-prima utilizada.

A sinterização é um processo em que a economia de material é levada ao extremo, com mínimas perdas de matéria-prima. Certas ligas podem ser obtidas pela metalurgia do pó a custos muitas vezes inferiores àquelas produzidas pela metalurgia convencional. A teoria da sinterização comprova que, ao se aquecer o compactado verde a uma temperatura maior que a metade da temperatura de fusão do material, ocorre união entre as partículas metálicas e estas tendem a alcançar as características físicas, químicas e mecânicas intrínsecas do material.

A metalurgia do pó envolve uma seqüência de processamento que permite fabricar diversos componentes a partir de pós metálicos. Esse processo envolve três etapas fundamentais: obtenção do pó, a compactação e a sinterização. Essa técnica permite a fabricação de componentes na qual a metalurgia é a única rota de fabricação a possibilitar a automação em linhas de produção [3]. 


\subsubsection{Obtenção de pós de ferro}

A produção de pós metálicos é influenciada pelos requisitos de: consolidação, aplicação dos produtos e custo de fabricação. Os processos de produção de pós metálicos podem ser divididos em: mecânicos (cominuição de metais e moagem de alta energia), químico (redução de um composto em estado sólido e decomposição térmica), eletroquímico, atomização (gás, água e centrífuga) e outros processos (vaporização e reações de síntese para pós intermetálicos). Entre os processos mencionados, os mais utilizados na produção de pós de ferro são: redução em estado sólido e atomização [2].

A redução em estado sólido é o método de obtenção do pó metálico por técnicas químicas, destacando-se a reação de composição de um sólido por meio gasoso. Nesta técnica, um concentrado de óxido de ferro, previamente moído para diminuição do tamanho da partícula é reduzido pela presença de um redutor gasoso ou sólido. O comportamento durante o processo e o tamanho de partícula obtido depende da temperatura de redução.

A atomização é um processo de produção de pós metálicos, em larga escala, que consiste na pulverização de um filete de metal líquido pela incidência de um fluído (líquido ou gasoso) de alta pressão. A elevada velocidade de resfriamento das partículas, combinada com técnicas de consolidação tem propiciado o desenvolvimento de novas ligas, com reduzida segregação e refinamento macroestrutural. As ligas de pós de ferro (aços baixa liga, inoxidáveis, e rápidos) são materiais fabricados comumente por atomização.

\subsubsection{A compactação dos pós}

A compactação visa consolidar pós e reduzir a fração de vazios (poros), isto é, elevar a densidade e aumentar a ligação entre partículas, com o objetivo de melhorar resistência a verde e facilitar o manuseio antes da sinterização. Segundo o tipo de compactação pode ser utilizados: pós e matrizes aquecidas ou a temperatura ambiente, matrizes moles ou duras, cilindros de laminação e ondas de choque. A Tab. 1 resume os processos de compactação mais usados na metalurgia do pó [2].

A compactação uniaxial a frio de pós é uma técnica bastante utilizada em linhas de produção e fabricação de componentes na forma quase final. Esta técnica 
é bastante utilizada no setor automobilístico, em conseqüência do baixo custo, poucas operações de acabamento, possibilidade de automatização e elevada reprodutibilidade. O processo consiste no preenchimento da cavidade da matriz, compactação, descarregamento da pressão e extração do compactado.

\subsection{A sinterização}

O processo de sinterização consiste em aquecer as partículas de pó, em temperaturas inferiores ao ponto de fusão, pelo menos um dos constituintes majoritários, com o objetivo de promover a união entre partículas. No processo de sinterização, as áreas de contato formadas durante a compactação apresentam redução da área superficial e do raio de curvatura, podendo ocorrer uma perda do contorno original da partícula. A movimentação dos átomos propicia a união das partículas, por meio da formação de um pescoço de sinterização, que eleva a resistência do sinterizado [6].

Tabela 1. Processos de compactação usados na metalurgia do pó.

\begin{tabular}{|c|c|c|c|c|c|c|c|}
\hline $\begin{array}{c}\text { Processo } \\
\text { propriedade }\end{array}$ & $\begin{array}{l}\text { Uniaxial } \\
\text { a frio }\end{array}$ & $\begin{array}{l}\text { Isostática } \\
\text { a frio }\end{array}$ & $\begin{array}{c}\text { Isostática } \\
\text { a quente }\end{array}$ & $\begin{array}{c}\text { Forjamento } \\
\text { a morno }\end{array}$ & $\begin{array}{l}\text { Uniaxial } \\
\text { a morno }\end{array}$ & $\mathrm{L}^{*}$ & $E$ * \\
\hline Pressão [Pa] & $7.10^{8}(\mathrm{~A})$ & $4.10^{8}(\mathrm{M})$ & $2.10^{8}(\mathrm{~B})$ & $8,10^{8}(\mathrm{~A})$ & $7.10^{8}(\mathrm{~A})$ & (B) & $1.10^{9}(\mathrm{~A})$ \\
\hline Temperatura da matriz ${ }^{\circ} \mathrm{C}$ & TA & TA & $1200(\mathrm{~A})$ & TA & $100-200$ & TA & $(\mathrm{A})$ \\
\hline Taxa de deformação & (A) & (B) & (A) & (A) & (A) & (B) & (A) \\
\hline Direção de deformação & 1 & 3 & 3 & 1 & 1 & 1 & 1 \\
\hline Complexidade geométrica & (A) & (M) & (B) & (M) & (M) & (B) & (B) \\
\hline Precisão & (A) & (B) & (B) & (M) & (A) & (A) & (B) \\
\hline Utilização & $(\mathrm{A})$ & (M) & (B) & (B) & (B) & $(\mathrm{M})$ & (B) \\
\hline
\end{tabular}

$L^{*}=$ laminação, $E^{*}=$ explosão, $(A)=$ alto, $(M)=$ moderado, $(B)=$ baixo, TA=temperatura ambiente. Adaptada de Neves (2005) [2]

A principal força motriz da sinterização é a redução de energia total do sistema, associada às áreas de superfícies livres e das interfaces. As tensões, decorrentes das superfícies e interfaces tendem a diminuir pela redução da área. Nos pós existe um excesso de energia atribuído a elevada área de superfície. Durante a sinterização a área de superfície é diminuída pelo aumento da área de contacto. Para assegurar a continuidade da sinterização é necessário que os átomos 
tenham mobilidade suficiente para atingir novas posições. A mobilidade atômica depende da temperatura. A energia para ocorrer a sinterização é proveniente da energia de superfície. Em pós irregulares e finos a energia total é maior dos que em pós esféricos de maior granulometria.

Dois fatores contribuem para a sinterização: movimentação atômica e as tensões relacionadas, a curvatura das superfícies e as interfaces. A relação entre as tensões $(\sigma)$ geradas pelas forças capilares e as tensões da superfície são dadas pela equação de Laplace [2], equação 1:

$$
\sigma=\gamma\left(1 / r_{1}+1 / r_{2}\right)
$$

onde;

$$
\begin{aligned}
& \gamma=\text { tensão de superfície } \\
& r_{1} \text { e } r_{2}=\text { raios de curvatura de partículas em contato }
\end{aligned}
$$

As tensões calculadas pela relação de Laplace causam um gradiente no potencial químico entre as superfícies de diferentes raios de curvatura. As tensões na sinterização são de pequena intensidade e a movimentação atômica é o fenômeno dominante. A movimentação nos pós de ferro, à temperatura ambiente, é pequena, no entanto, aumenta significativamente com a elevação da temperatura.

A equação de Arrhenius descreve os fenômenos de difusão atômica e mostra a dependência da temperatura com a movimentação atômica conforme equação 2:

$$
\mathrm{D}=\mathrm{D}_{\mathrm{o}} \exp (-\mathrm{Q} / \mathrm{RT})
$$

na qual:

$$
\begin{aligned}
& D=\text { difusividade }\left[\mathrm{m}^{2} / \mathrm{s}\right], \\
& D_{0}=\text { fator pré-exponencial (fator de freqüência) }\left[\mathrm{m}^{2} / \mathrm{s}\right], \\
& R=\text { constante universal dos gases }[\mathrm{cal} / \mathrm{molK}], \\
& T=\text { temperatura absoluta }[\mathrm{K}] \mathrm{e} \\
& Q=\text { energia de ativação }[\mathrm{cal} / \mathrm{mol}]
\end{aligned}
$$


O movimento atômico depende da energia de ativação [Q]. A energia de ativação é composta pela soma das parcelas $\left[Q_{B}+Q_{N}\right]$. $O$ valor $Q_{B}$ refere-se à energia (vibração) do átomo para quebrar as ligações existentes com átomos vizinhos e a parcela $Q_{N}$ é a energia associada à formação de sítios de lacunas próximo ao átomo. A equação de Arrhenius pode ser reescrita levando em consideração estas parcelas, conforme a relação, equação 3:

$$
N_{A}=N_{O} \exp \left[-\left(Q_{B}+Q_{N}\right) / R T\right]
$$

$\mathrm{Na}$ qual: $\mathrm{N}_{\mathrm{A}} / \mathrm{N}_{\mathrm{o}}$ representa o número de locais disponíveis ou de átomos com energia suficiente para se movimentar em relação ao número total de átomos.

A sinterização, que é realizada em fornos especiais, geralmente ocorre em temperaturas que variam entre $70 \%$ e $80 \%$ da temperatura de fusão do metal ou liga metálica considerada, sob condições muito bem controladas de temperatura, tempo e ambiente, sendo esta última etapa a que propicia a resistência mecânica e outras propriedades ao material compactado [4].

Embora a aplicação da metalurgia do pó seja indicada para a maioria produções. Entretanto, algumas limitações ainda precisam ser superadas em alguns casos, como peça com características geométricas especiais que dificultam sua extração da matriz. Dado que o custo de produção do ferramental ser muito elevado, o método só se justifica para produção de grades volumes [6].

Diante do exposto, ressalta-se a importância da metalurgia do pó para o aumento da competitividade das empresas, tanto as que utilizam, como as que venham utilizar esta técnica de fabricação. Dentre os quatro elementos (Fig. 2) que compõem a área da ciência e engenharia de materiais - "síntese e processamento", "composição e estrutura", "propriedades" e "desempenho", a síntese e processamento é o elemento básico para a produção de materiais com propriedades superiores e melhor desempenho. Isto implica também em produtos de melhor qualidade, sendo este um fator determinante da produtividade industrial. 


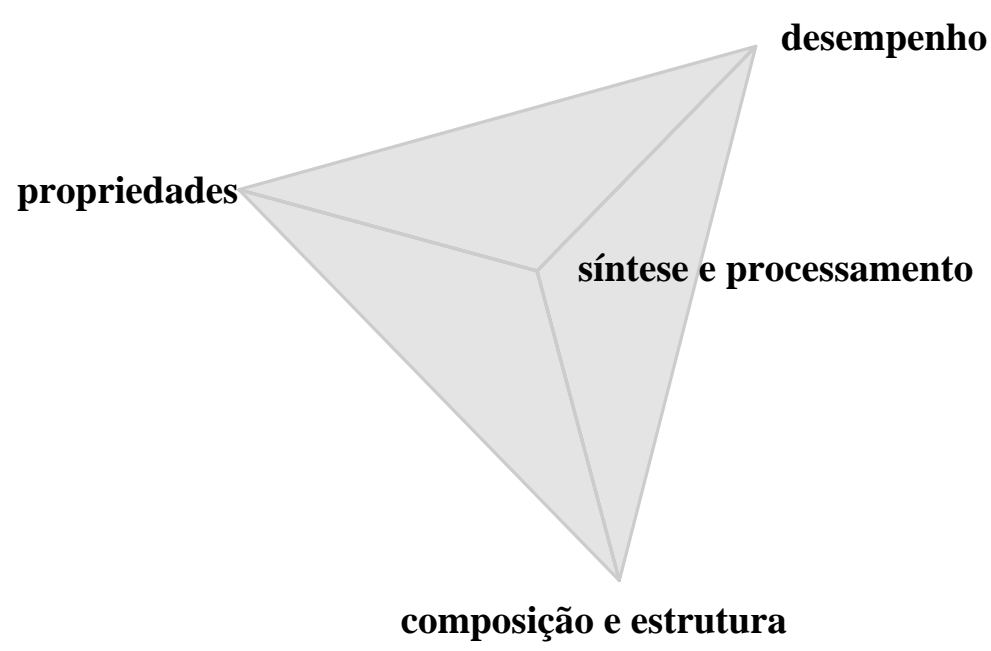

Figura 2. Representação da área de ciência e engenharia de materiais por um tetraedro.

Através de projetos de pesquisa, busca-se viabilizar o surgimento de processos competitivos para a produção de bens materiais, objetivando: inovação de processos e produtos; redução de custos e melhoria da qualidade; otimização de recursos físicos e humanos; melhoria da capacitação tecnológica e da competitividade industrial.

\subsection{Aspectos gerais da produção}

Embora o objetivo deste trabalho seja estudar a produção de uma peça específica, cabe aqui distinguir os conceitos de produção e operação. A produção diz respeito àquelas atividades orientadas para a produção de um bem físico o que dá a idéias de uma atividade industrial. Já a operação refere-se à prestação de um serviço. Observa-se que em uma organização, mesmo de caráter industrial, um conjunto de serviços são gerados internamente. De qualquer maneira, neste estudo utilizar-se-á a expressão produção para designar as atividades de transformação ou de geração de um serviço.

O estudo da produção, ao longo dos anos foi feito de várias abordagens diferentes. Objetivando restringir o tema aos objetivos deste trabalho, destacam-se: a produção como um sistema, a produção como uma função organizacional e a tomada de decisões. 


\subsubsection{A produção como um sistema}

O entendimento dos conceitos que envolvem a teoria dos sistemas é útil para entender a produção como um sistema. Dessa forma, vale lembrar Akcoff: "Um sistema é um todo que não pode ser separado sem que ocorra a perda de suas características essenciais, por isso, deve ser estudado como um todo. Agora, em vez de explicarmos um todo de suas partes, as partes começaram a ser estudadas em termos de todo" [7].

Um sistema de produção recebe insumos na forma de material, pessoal, capital, serviços públicos e informação. Esses insumos são modificados num subsistema de transformação para o produto desejado. Uma parcela do produto é monitorada no subsistema de controle para determinar se ele é aceitável em termos de quantidade, custo e qualidade. O subsistema de controle assegura o desempenho do sistema, ao fornecer feedback aos responsáveis pela produção para que possam tomar ações corretivas, vide Fig. 3.

Vale lembrar, também, a definição de sistema de produção dada por Moreira que um sistema de produção é um conjunto de atividades e operações interrelacionadas envolvidas na produção de bens (caso de indústrias) ou serviços [8].

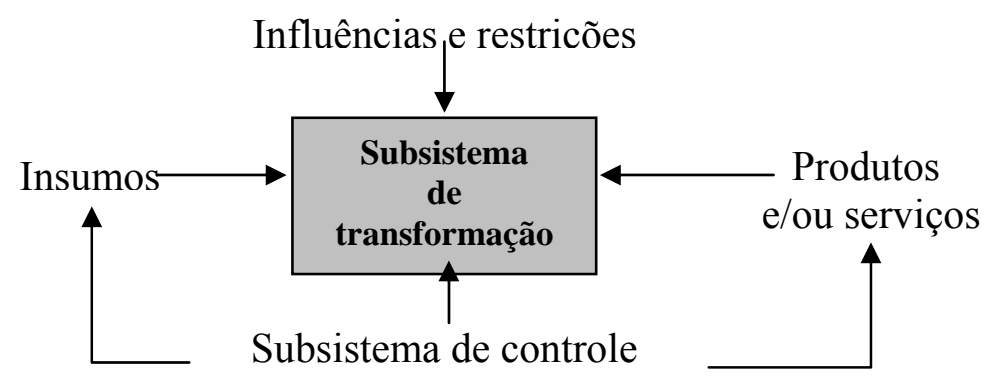

Figura 3. Elementos do sistema de produção.

\subsubsection{A produção como função organizacional}

Do ponto de vista da produção como função organizacional, observa-se que o ponto crucial de um sistema de produção é seu subsistema de transformação, pois é ali que todo o esforço de produção se concentra para transformar os insumos da produção em produto e isso se dá através da alocação da mão-de-obra, matériasprimas e máquinas; assim gerando produtos ou serviços. Dessa forma, a 
transformação de insumos ou a geração de serviços está presente em todas as organizações. Os responsáveis pela produção, respondem, de fato, por todas as atividades dos sistemas de produção que transforma insumos em produtos e serviços da organização. Assim, cada ação significa uma tomada de decisão.

\subsubsection{A tomada de decisão}

É aqui, na análise da produção que se encontra o espaço propício para a aplicação de procedimentos formais de análise de problemas de decisão. A tomada de decisão envolve uma situação problema, onde se depara com várias alternativas de solução. Na maioria dos casos um problema apresenta várias soluções viáveis, competindo ao tomador de decisão pesquisar tais soluções e identificando aquela mais viável.

Pode-se classificar as decisões em estratégicas, operacionais e de controle. As decisões estratégicas são aquelas de impacto de longo prazo sobre a organização, são decisões sobre produtos, processos e instalações. As decisões operacionais referem-se ao planejamento da produção para atender a demanda, ou seja se a produção contínua de bens e serviços pretende satisfazer as exigências do mercado. As decisões de controle dizem respeito ao planejamento do controle das operações. Essas decisões privilegiam as atividades diárias dos trabalhadores, a qualidade dos produtos e serviços, os custos de produção e gastos gerais e a manutenção de máquinas. [9].

Todo problema de decisão também apresenta o que se pode chamar genericamente de dados, que nada mais são do que um conjunto de informações a partir das quais, o problema será analisado [8]. Dessa forma, deve-se ponderar que as informações têm natureza e variedades conforme cada caso. Um problema mal estruturado é caracterizado por apresentar poucas informações e muitas dúvidas sem uma resposta precisa. Por outro lado, problemas com dados bem definidos, geralmente numéricos, onde inexistam indagações sem respostas, são chamados problemas bem estruturados.

A análise formal de problemas de decisão é geralmente levada a efeito através de modelos matemáticos, procurando enquadrar o problema em um dos muitos modelos já disponíveis e de utilidade comprovada. 


\subsubsection{A modelagem de dados}

O processo de se transformar os dados de um problema e organizá-los segundo as necessidades formais de um modelo matemático chama-se modelagem. A modelagem de dados requer que o problema seja bastante estruturado de forma a se obter o maior volume possível de dados quantificáveis; dessa forma será possível uma solução matemática do problema. No entanto, dificilmente se ataca um problema apenas com análises quantitativas, pois se tem que levar em conta alguns fatores qualitativos que são também considerados fatores imponderáveis.

O processo de análise quantitativa pode se descrito numa seqüência de cinco passos [8]:

a) definição do problema;

b) desenvolvimento do modelo;

c) preparação dos dados;

d) solução do modelo;

e) relatório dos resultados.

A definição do problema é a fase mais crítica do processo de análise quantitativa, consistindo na transformação das descrições genéricas em um problema bem estruturado que possa ser abordado quantitativamente, definindo de forma clara e precisa os objetivos que se pretende com a solução e as restrições que cercam o problema, vide Fig. 4.

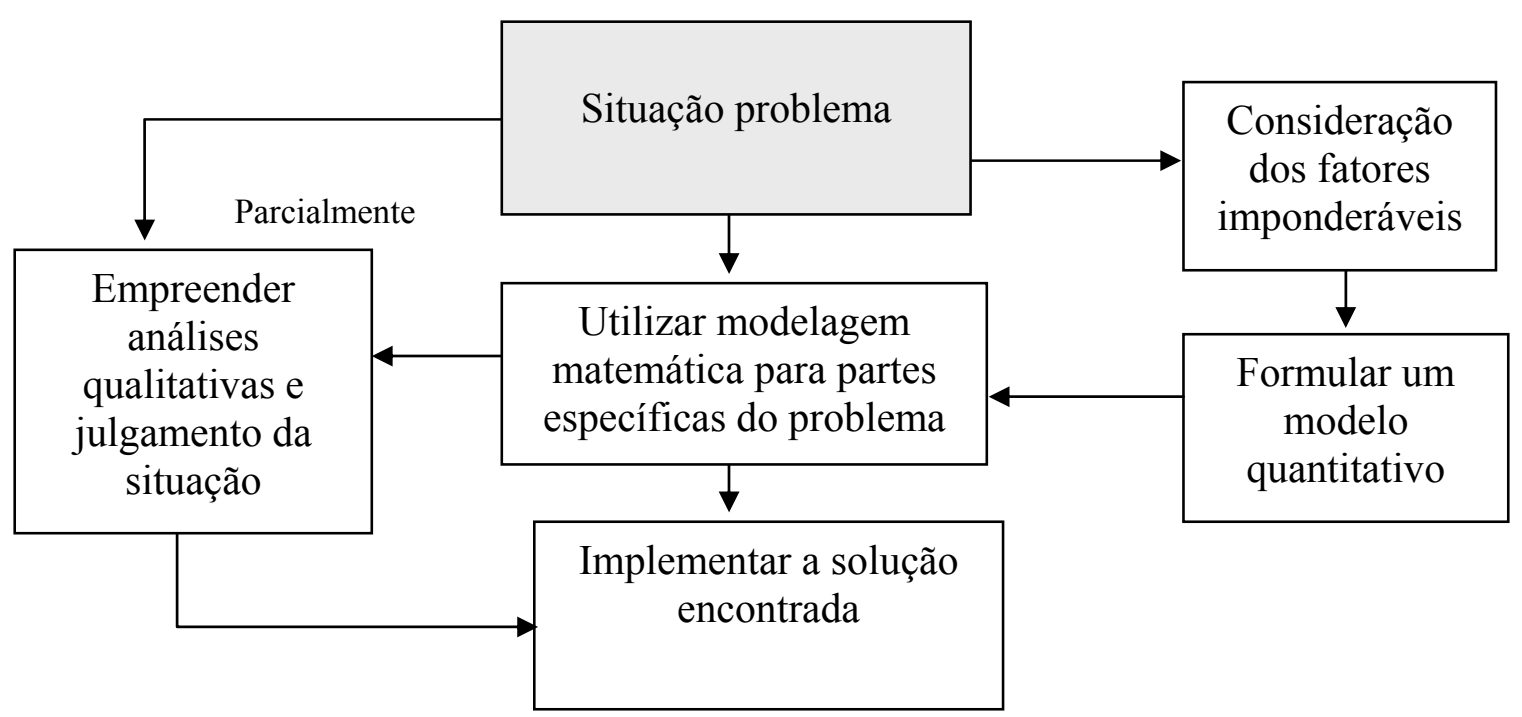

Figura 4. Abordagem a um problema de decisão. 
O desenvolvimento do modelo requer que se estabeleça representação simplificada de objetos e situações reais. Podem ser de três tipos: iônicos - são réplicas de um objeto real em tamanho diferente ou não; analógicos - são modelos físicos, mas não guardam a forma do objeto que está sendo representado; e os matemáticos - são aqueles em que a situação problema ou as propriedades de um objeto são representadas por um sistema de símbolos e relações matemáticas passíveis de manipulação na busca de uma solução ou no estudo do comportamento do objeto sob certas condições.

A preparação dos dados requer que o analista identifique as variáveis que são classificadas em variáveis não controladas e variáveis de decisão. As variáveis não controladas são aquelas definidas pela situação, pela estrutura do problema, pelas características da organização ou pelas restrições; assumem valores que não podem ser controlados, mas dos quais se conhece o valor, conjunto de valores ou distribuição de probabilidades. As variáveis de decisão são aquelas cujo valor deve ser determinado pelo analista, através do modelo, constituindo-se assim em solução ao problema colocado.

\subsubsection{A solução do modelo}

A solução do modelo ocorre após a coleta dos dados quando se para a solução do problema, tentando especificar os valores das variáveis que forneçam a melhor saída do modelo, segundo critérios pré-definidos. Esses valores das variáveis de decisão são chamados de solução ótima.

\subsubsection{Relatório de resultados}

O relatório de resultados é o passo final do processo de análise quantitativa. Os resultados obtidos, junto com as considerações de ordem qualitativa (fatores imponderáveis) que não entram no modelo, serão enviados ao tomador de decisão para a decisão final. O relatório deve conter a solução recomendada e quaisquer outras informações úteis sobre o modelo. 


\subsection{Controle estatístico de processos}

\subsubsection{Definições}

Pode-se definir controle estatístico através da junção dos significados de cada uma das palavras:

- Controle - manter algo dentro dos limites ou padrões previamente definidos ou fazer algo se comportar de forma adequada.

- Estatística - obter conclusões com base em dados. A estatística é a parte da matemática aplicada que se ocupa em obter conclusões a partir de uma série de dados e números observados. Através dessas observações, pode-se chegar a diversas conclusões sobre o conjunto todo. Por exemplo: o número de defeitos; a percentagem de peças defeituosas; custo médio; freqüência média esperada de acidentes; custo médio etc. Assim, devido suas características, o uso da estatística se torna muito importante por poder prever científica e racionalmente que medidas tomar a fim de melhorar os resultados futuros de um sistema.

- Processo - é a combinação necessária entre os homens, os materiais, as máquinas, os equipamentos e o meio ambiente, para produzir um produto qualquer. Mais especificamente, um processo é qualquer conjunto de condições ou conjunto de causas que trabalham para produzir um determinado resultado.

Das diversas definições apresentadas na literatura, parece ser unanimidade que processo é um conjunto de causas (input) que tem como objetivo produzir um determinado efeito, o qual é denominado de produto de processo. A Fig. 5 apresenta graficamente o conceito de Ishikawa [10].

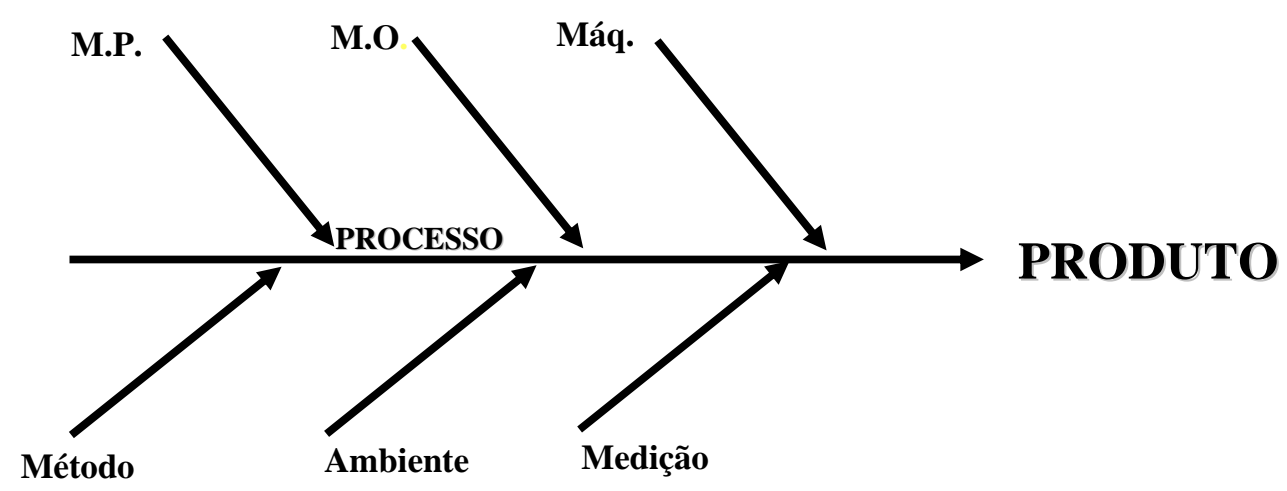

Figura 5. Diagrama de Ishikawa. 
Dessa forma deve-se entender o controle estatístico do processo como um método preventivo de se comparar continuamente os resultados de um processo com os padrões, identificando, a partir de dados estatísticos, as tendências para variações significativas, eliminar; controlar as variações com o objetivo de reduzir cada vez mais essas variações.

Considerando que o CEP corresponde ao conjunto de técnicas que são desenvolvidas a partir de um princípio básico: ao invés de trabalhar com um valor único para medida de um dado característico de qualidade, admite-se que todos os processos variam, e por isso utiliza-se uma faixa de variação, dentro da qual todos os resultados são considerados aceitáveis.

Com relação às causas de variações, afirma-se que existem dois tipos, as causas aleatórias ou acidentais e as causas assinaláveis. As causas aleatórias provocam variações naturais nos produtos sendo, portanto, inerente ao produto, o que inviabiliza sob o ponto de vista físico ou econômico a sua eliminação. A presença de outras causas no processo provoca variações anormais, sendo que tais causas devem ser detectadas e corrigidas. Com relação a essas considerações, cabe colocar que, para cada processo em particular, em função de suas peculiaridades, deve-se definir o que são causas aleatórias e causas assinaláveis.

\subsubsection{O controle estatístico de processo}

Desde os anos 1920, já se conhece uma ferramenta de análise dos processos de produção conhecido como controle estatístico de processos - CEP, método esse desenvolvido por Shewhart [6]. Ele apresenta técnicas de medição, parâmetros de comparação, ferramentas de análise e decisão bem como técnicas de otimização de processos. Além disso, o controle baseado na variabilidade estatística fornece a possibilidade de verificar se o processo se comporta de forma esperada ou de forma imprevisível orientando os gestores dos processos na sua otimização ou na alocação de investimentos. O uso do CEP fornece um parâmetro de avaliação da estabilidade do processo e sua capacidade de gerar produtos que atendam às especificações legais ou mercadológicas [7]. A aplicação do CEP permite então a otimização dos recursos envolvidos em processo produtivo através da competente ação gerencial no aperfeiçoamento da qualidade e a produtividade. 
Com o CEP pode-se analisar cientificamente dados e informações sobre qualquer processo, aplicando em qualquer coisa que possa ser expressa em números e cujos resultados finais impliquem em alguma expectativa de semelhança ou repetibilidade ao longo do tempo. Com o CEP é possível aproveitar melhor os equipamentos e máquinas, a mão-de-obra e os demais recursos, o que permite desenvolver competente ação gerencial para aperfeiçoar a qualidade e a produtividade.

A abordagem estatística está baseada no conceito de controle através da prevenção, oposto ao controle através da correção. O controle através da correção baseia-se na inspeção após o fato para separar produtos aceitáveis de produtos não aceitáveis. Baseado nessa informação é que o sistema é ajustado. Obviamente isso causa perdas devido a duas importantes razões:

- custa a mesma coisa produzir um produto aceitável ou um produto não aceitável;

- um produto aceitável precisa ser reparado ou precisa ser fabricado novamente, o que aumenta o custo de produção.

Um sistema monitor que detecta as falhas e faz os ajustes necessários antes que produtos ruins sejam fabricados seria o ideal. É isso que caracteriza o controle preventivo do CEP, utilizado com base na estatística durante a fabricação.

Com o CEP pode-se analisar cientificamente dados e informações sobre o andamento dos processos e utilizar os resultados da análise para identificar e eliminar as causas-raízes dos problemas, resolvendo-os de forma completa e definitiva. Pode ser aplicado em qualquer coisa que possa ser expressa em números e cujos resultados finais impliquem em alguma expectativa de semelhança ou repetibilidade ao longo do tempo.

Dentre as diversas ferramentas do CEP, os gráficos de controle são as mais importantes e estes possuem três objetivos básicos:

- Verificar se o processo estudado é estatisticamente estável, ou seja, se não há presença de causas especiais de variação;

- Verificar se o processo estudado permanece estável, indicando quando é necessário atuar sobre ele; e 
- Permitir o aprimoramento contínuo do processo, mediante a redução de sua variabilidade.

Os gráficos de controle trabalham com flutuações observadas ao longo do processo. Tais flutuações representam as variações sofridas pelos dados referentes ao processo. Com a observação dos limites estabelecidos no próprio gráfico, verifica-se se o processo se comporta de forma satisfatória ou não, como pode se identificar, por exemplo, em qual época ocorrem as variações.

As variações, em geral, denunciam a presença de problemas no processo. No caso de existirem grandes variações, conclui-se da existência de problemas importantes no processo, os quais devem ser descobertos, além de descobrir as causas geradoras de tais problemas.

Pode-se destacar como resultados positivos quando da utilização dos gráficos de controle, a melhoria e garantia da qualidade, a redução de custos, crescente desaparecimento de refugos e outros. Os gráficos de controle mais conhecidos são o controle por variáveis e o controle de atributos. O controle por variáveis é baseado na distribuição normal, que é o modelo estatístico clássico, além de se utilizar medidas físicas como, por exemplo, o diâmetro de um eixo ou uma medida de tempo qualquer.

Dentre os gráficos de controle por variáveis, destacam-se: gráfico da média; gráfico do desvio-padrão e gráfico da amplitude. O controle por atributos pode ser apresentado por dois tipos básicos de avaliação, sendo que esta pode ser feita em termos de peças defeituosas ou em termos de defeitos observados.

Os atributos são características da qualidade que resultam de uma operação de contagem após a avaliação de conformidade. O item inspecionado é apenas classificado em conforme (se está de acordo com as especificações) ou nãoconfome (se não está de acordo com as especificações).

Nos gráficos de controle por atributos, destacam-se: gráfico de fração defeituosa; gráfico de número de peças defeituosas; gráfico de número de defeitos por unidade; gráfico de número de defeito por amostra [9].

A seleção do tipo de gráfico tem indicação precisa, de acordo com o tamanho 
das amostras e quantidades de tipo de análise a ser conduzida face à quantidade de defeitos por produto, um único tipo de defeito e vários tipos de defeito.

A carta de controle típica de Shewhart exibe três linhas paralelas: a central, que representa o valor médio (LM); superior, que representa o limite superior de controle (LSC); e a limite inferior de controle (LIC), Fig. 6.

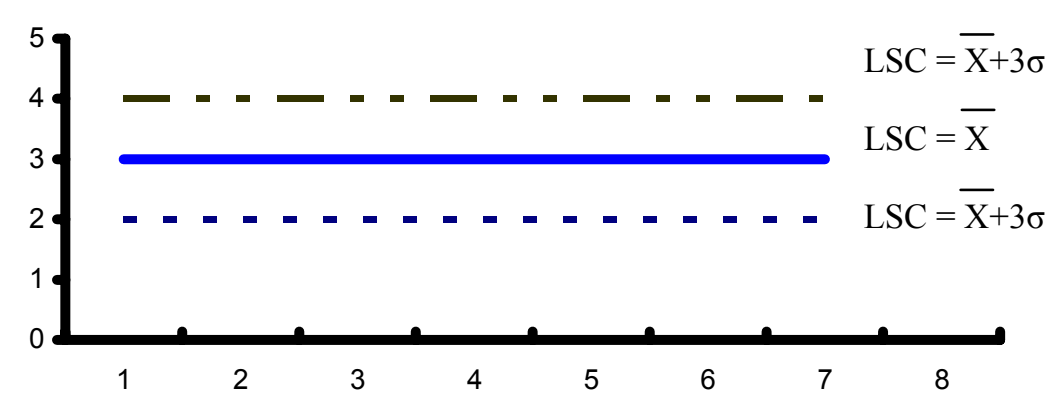

Figura 6. Gráfico de controle de Shewhart.

Esses limites são mais comumente dispostos $3 \sigma$ acima e $3 \sigma$ abaixo deste valor alvo, resultando que em um processo sob controle há aproximadamente $0,27 \%$ de probabilidade de um ponto cair fora desses limites [10].

Os gráficos de controle, desenvolvidos por Shewhart, admitindo um processo estatístico estável, com média e desvio padrão estáveis terá seus limites de controle assim calculados [11], equações 4:

$$
\begin{aligned}
& \operatorname{LS}=\bar{x}+3 \sigma \\
& \operatorname{LSC}=\bar{x} \\
& \operatorname{LIC}=\bar{x}-3 \sigma
\end{aligned}
$$

Pelo fato de que as médias amostrais tendem a ter distribuição normal, por força do teorema do limite central, e, também em virtude da variância do processo (ou valores individuais), é de praxe adotarem-se gráficos do tipo médio (x-barra) e amplitude (R) [12].

O teorema do limite central presume que as distribuições amostrais estão distribuídas normalmente mesmo que a distribuição da população não seja normal [13]. Esses são de uso mais freqüente em todo tipo de indústria. Os limites de controle para o gráfico da média são, equações 5 : 


$$
\begin{aligned}
& L S C=\overline{\bar{X}}+A_{2} \cdot \bar{R} \\
& L M=\overline{\bar{X}} \\
& L S C=\overline{\bar{X}}-A_{2} \bar{R}
\end{aligned}
$$

Onde $x$ duas barras é a média geral das amostras $k$ obtidas. $A_{2}$ é definido como, equação 6:

$$
2=\frac{3}{d_{2} \cdot \sqrt{n}}
$$

Com $\mathrm{d}_{2}$ sendo um fator de correção do viés introduzido pela substituição de $\sigma$ por R-barra. R-barra é a amplitude média definida como, equação 7:

$$
\overline{\mathrm{R}}=\frac{\sum \mathrm{R}_{\mathrm{i}}}{\mathrm{k}}
$$

O gráfico X-barra é utilizado conjuntamente com o gráfico da amplitude $(R)$, que possui como limites de controle, equações 8:

$$
\begin{aligned}
\mathrm{LSC}_{\mathrm{R}} & =\mathrm{D}_{4} \cdot \overline{\mathrm{R}} \\
\mathrm{LM}_{\mathrm{R}} & =\overline{\mathrm{R}} \\
\mathrm{LIC} & =\mathrm{D}_{3} \cdot \overline{\mathrm{R}}
\end{aligned}
$$

onde $D_{3}$ e $D_{4}$ também são fatores de correção, em função do tamanho da amostra (n).

Uma das particularidades dos gráficos de controle é que ao observar o seu comportamento, pode-se dizer se o processo está, ou não, sob controle estatístico. Assim, se todos os pontos traçados no gráfico (Fig. 7) estiverem dentro dos limites de controle sem qualquer tendência particular, ou seja, a disposição dos mesmos é aleatória, afirma-se que o processo está sob controle estatístico. Caso contrário, um ou mais pontos fora dos limites de controle ou distribuição não aleatória, o processo é considerado fora de controle estatístico e demanda investigação. 


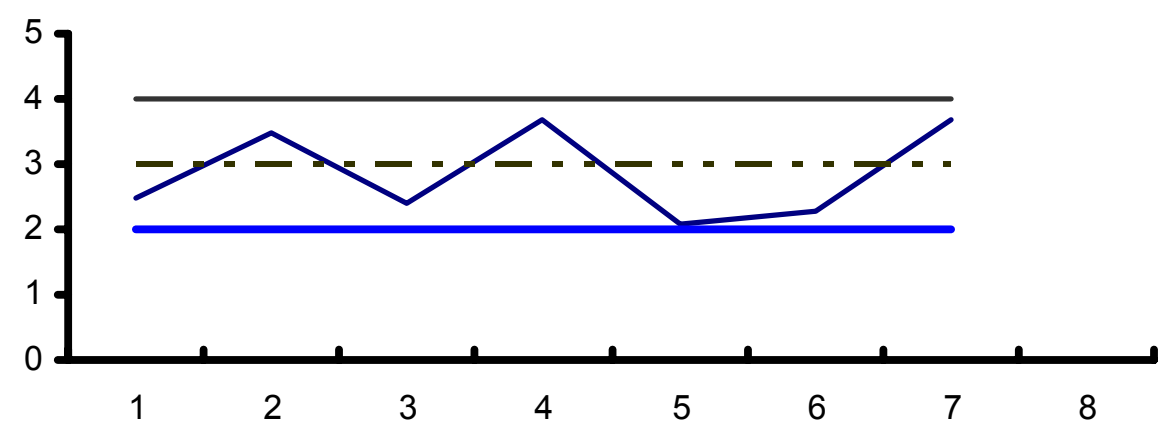

Figura 7. Processo sob controle estatístico.

A estabilidade do processo é representado pela distribuição dos pontos dentro dos limites de controle. Enquanto que a instabilidade,é representada pelos seguintes parâmetros [14]:

- Pontos fora dos limites de controle - um ponto acima do LSC ou abaixo do LIC, vide Fig. 8. Pontos fora dos limites podem ser fruto de variação de causas especiais, assim, deve-se identificar os fatores que causam esta variação e eliminar estes pontos. A partir do momento que se deixa de ter pontos fora dos limites de controle, a atenção passa para o estudo do comportamento não-aleatório, que caracterizaria o processo como estando fora de controle.

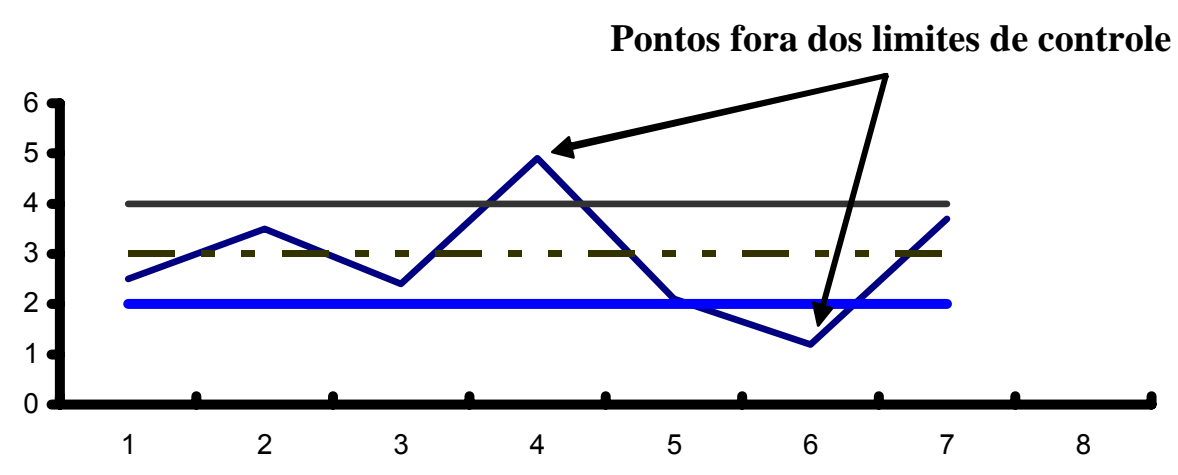

Figura 8. Processo fora de controle estatístico.

- $\quad$ presença de ciclos ou tendências nos pontos - seis pontos consecutivos aumentando ou diminuindo. A Fig. 9 é o exemplo típico da presença de tendências com vários pontos se direcionando para baixo e para cima. Isso, geralmente ocorre com o desgaste de ferramentas. 


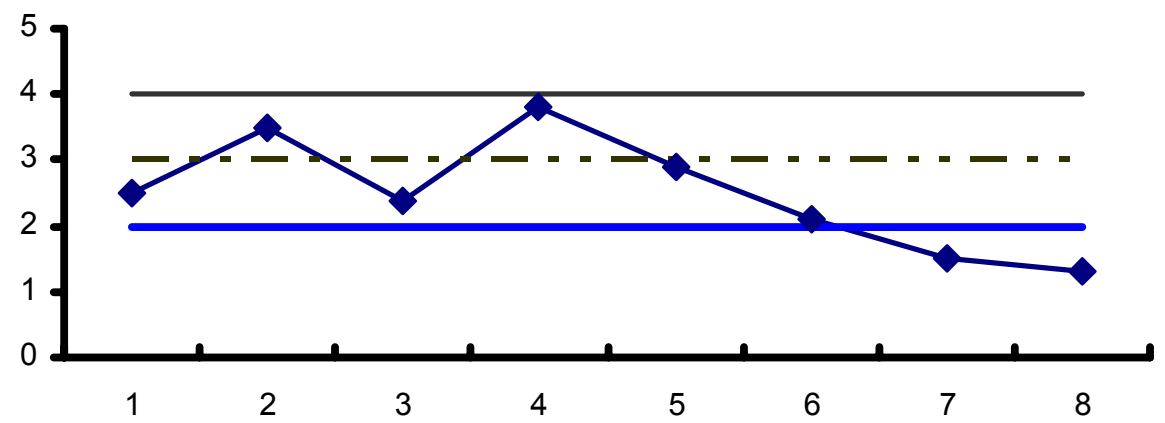

Figura 9. Exemplo de tendência em gráfico de controle.

- Estratificação ou falta de variabilidade - é representado quinze pontos consecutivos próximo à LM (terço médio), quatorze pontos consecutivos alternandose para cima e para baixo. Na falta de variabilidade a linha de dados se posiciona próxima à linha central, como mostra a Fig. 10a), normalmente fruto de erros de coleta (dados falsos) ou seleção imprópria de subgrupos racionais. No caso de excesso de variabilidade a linha assume um comportamento inverso, com "piques" extremos de comportamento, como mostra a Fig. 10b), resultado de ajustes freqüentes de máquinas ou interferência de outros níveis de fatores de causa de variação que normalmente justificaria uma melhor estratificação dos dados.

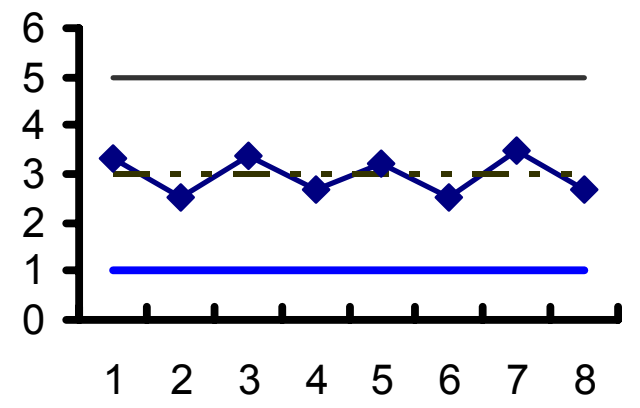

(a) Falta e variabilidade

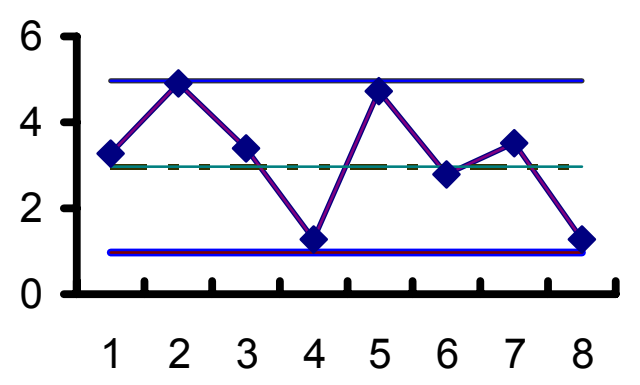

(b) Excesso de variabilidade

Figura 10. Exemplo de estratificação ou falta de variabilidade.

- $\quad$ Seqüência - Situação em que pontos consecutivos incidem em um dos lados da linha central. Esta seqüência de pontos se chama de "comprimento da seqüência". Considera-se como sendo anormal uma seqüência de 7 pontos (Fig. 11a), ou até mesmo uma seqüência com menos de 6 pontos mas que de $80 \%$ dos 
pontos do gráfico se localizam de um só lado da linha central (Fig. 11b).

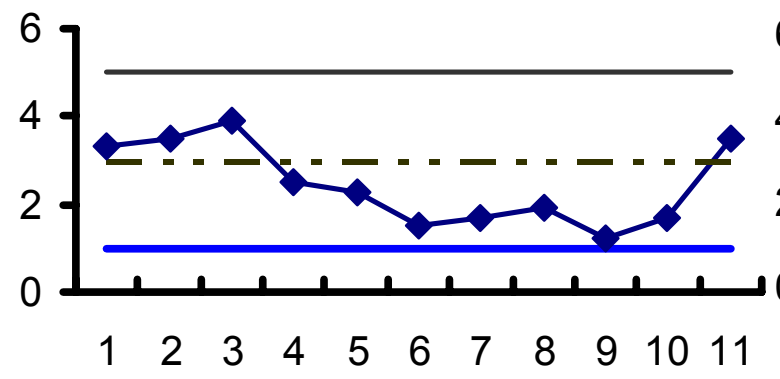

(a) Seqüência de 7 pontos

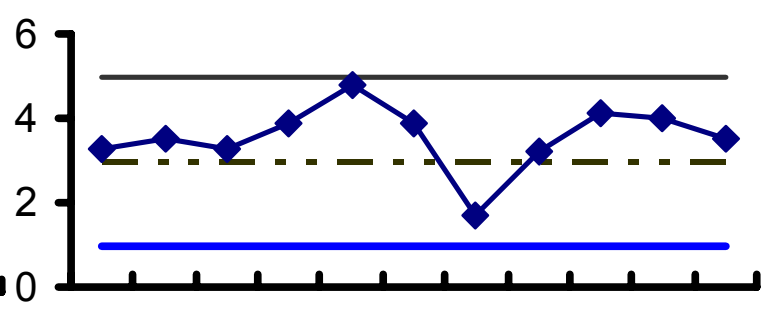

$\begin{array}{lllllllllllll}1 & 2 & 3 & 4 & 5 & 6 & 7 & 8 & 9 & 10 & 11\end{array}$

(b) $80 \%$ dos pontos de um só lado

Figura 11. Exemplo de seqüência.

- $\quad$ Periodicidade ou ciclos - Quando a linha apresenta subidas e descidas em intervalos regulares de tempo (Fig. 12), associado normalmente quando uma das condições do processo (ex. temperatura, operador, turno) sofre mudanças periódicas.

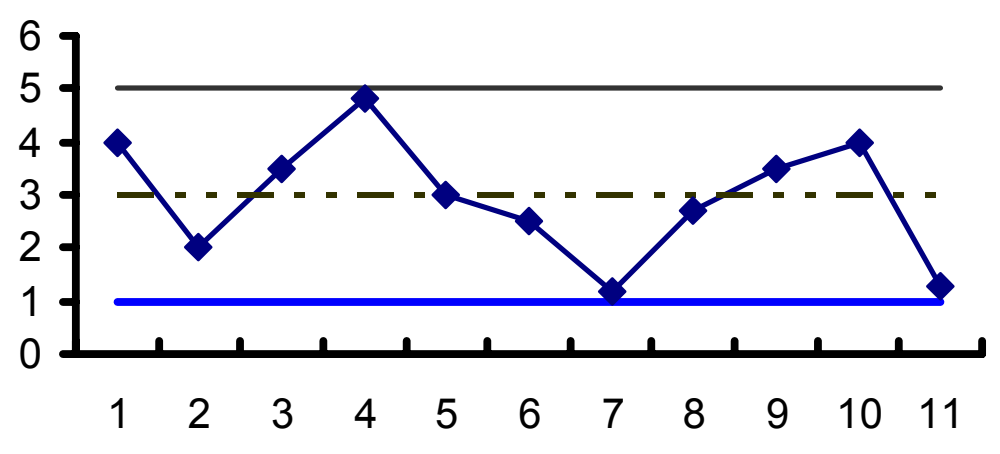

Figura 12. Exemplo de periodicidade em gráfico de controle.

- Deslocamento - Quando apresenta mudança no nível de desempenho do processo (Fig. 13), normalmente justificada por introdução de novas máquinas, novos métodos ou até mesmo de um programa de qualidade. 


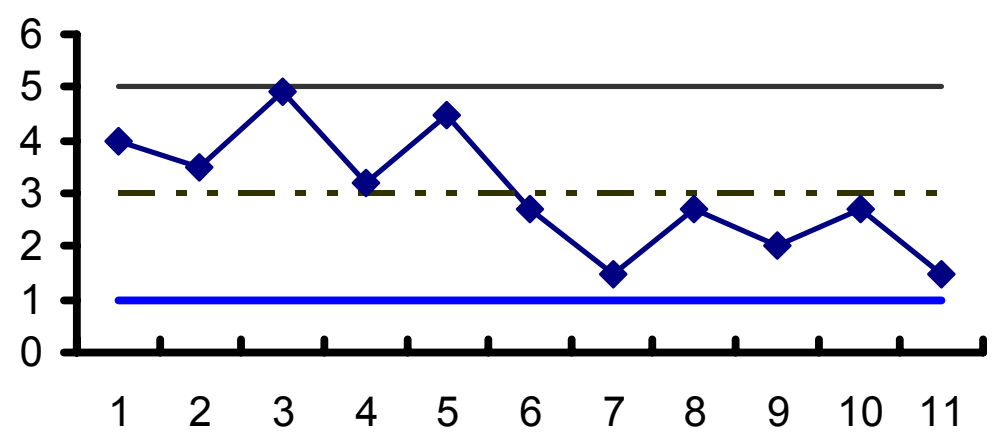

Figura 13. Exemplo de deslocamento em gráfico de controle.

A implantação do CEP percorre um ciclo onde após escolhido o processo a ser estudado, define-se o item a ser controlado, coleta-se os dados do processo, monitora-se sua situação (verificando se o mesmo permanece sob controle estatístico) oferecendo indicadores para o gerenciamento do desempenho.

Para Ramos [15], mais importante do que o tipo de gráfico de controle utilizado, é a ação tomada sobre um processo quando este é instável. Os gráficos de controle funcionam apenas como "vigilantes" da estabilidade estatística do processo, mas é a gerência quem deve determinar as ações a serem tomadas. O raciocínio estatístico é tão somente uma ferramenta de apoio à tomada de decisão, ou seja, é um meio e não um fim em si mesmo, vide Fig. 14. 


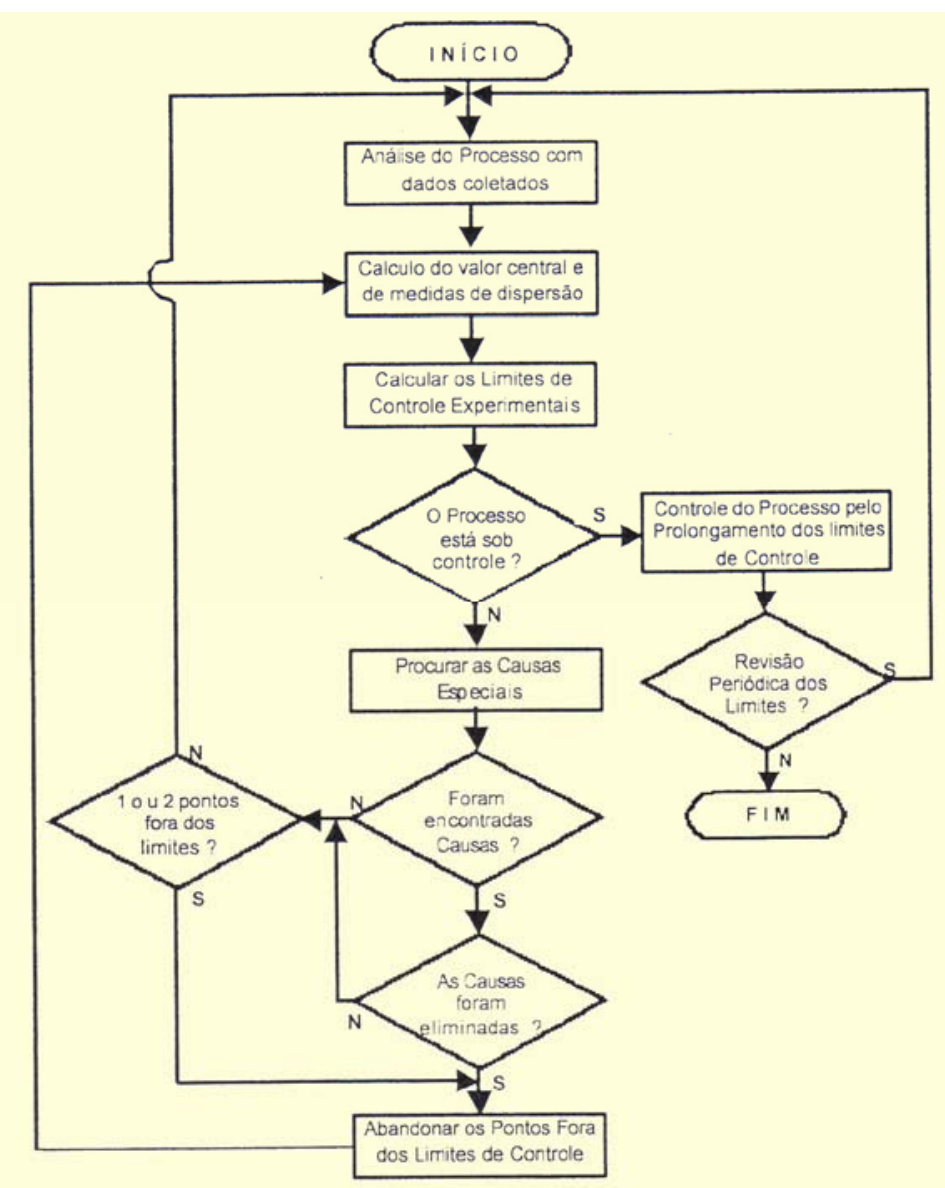

Figura 14. Fluxograma do controle estatístico do processo.

\subsubsection{Capabilidade do processo}

A capabilidade de processos se refere a um comportamento específico do mesmo, o qual pode ser identificado por características, como a não influência de agentes externos, a adequação a uma distribuição de freqüência bem definida e a previsibilidade de resultados. É um instrumento útil para se determinar se um processo de produção é capaz de produzir produtos à altura das expectativas [16].

A capabilidade de processos pode ser expressa de duas formas básicas: percentual de peças defeituosas; distribuição de medidas. Um estudo de capabilidade de processos é um procedimento contínuo, com forte embasamento científico e se utiliza, fundamentalmente, de uma técnica que requer a construção e análise de gráficos de controle. Dessa forma, verifica-se que os estudos da capabilidade de processos utilizam-se de uma estratégia bem definida, baseada na coleta e análise de informações relativas ao desempenho do processo. Tais estudos 
podem revelar: se o processo é uniforme ou não; se o processo tem condição de atender a um conjunto de especificações; como o processo varia; e as tendências naturais do processo.

O índice de capabilidade é obtido dos dados da carta de controle e eles medem a relação entre as faixas de tolerância especificadas para uma dada características de projeto do produto e a variabilidade natural do processo produtivo. Através do índice de capabilidade do processo se tem a probabilidade de produção fora da especificação, tanto acima do limite superior de controle quanto abaixo do limite inferior de controle. Ao observar altos índices, significa que o processo deve ser modificado ou adotar processos alternativos.

Estes índices são de extrema importância para o desenvolvimento de produto nas fases iniciais de projeto, permitindo a escolham processos e especificações dos produtos coerentemente adequadas, garantindo a obtenção de características do produto por meio de processos altamente capazes estatisticamente [17], equação 9.

$$
\mathrm{C}_{\mathrm{p}}=\frac{\mathrm{LSE}-\mathrm{LIE}}{6 \sigma}
$$

- $\quad$ LSC = limite superior da característica de um produto que pode ser incluída nas expectativas.

- $\quad$ LIC = limite inferior da característica de um produto que pode ser incluída nas expectativas.

- $\sigma=$ desvio padrão da característica de um produto ou processo de produção, uma medida de variação de longo prazo da característica de um produto dentro do processo de produção.

Cp pode assumir qualquer valor positivo e estes podem ser assim analisados:

- $\quad$ Se $\mathrm{Cp}<1,0$ o processo produtivo gera muito produtos abaixo do LIE e muitos acima do LSE.

- $\quad$ Se $\mathrm{Cp} \geq 1,0$ o processo produtivo tem capacidade de atender plenamente as expectativas gerando produtos totalmente dentro dos limites estabelecidos.

A seguir, destacam-se os índices de capabilidade Ramos [15]: 
- $\quad$ Capabilidade (Cp) (conhecido como capabilidade de máquina). Definido como o intervalo de tolerância dividido pela capabilidade do processo, ou seja, 6 vezes o desvio padrão estimado considerando a ausência de causas especiais. Ele é independente da centralização do processo o desvio padrão é estimado considerando processos estáveis, equação 10:

$$
C_{p}=\frac{L S E-L I E}{6 \hat{\sigma}_{R / d 2}}
$$

- Desempenho (Pp): Intervalo de tolerância dividido pelo desempenho do processo, ou seja, pelo desvio padrão estimado pelas leituras individuais. Também independentemente da centralização, equação 11.

$$
P_{p}=\frac{L S E-L I E}{6 \hat{\sigma}_{S}}
$$

- $\quad$ Superior de capabilidade (CPU): variação superior da tolerância dividida por 3 vezes o desvio padrão estimado pela capabilidade do processo, equação 12.

$$
C P U_{p}=\frac{L S E-\overline{\bar{X}}}{3 \hat{\sigma}_{S}}
$$

- Inferior de capabilidade (CPL): variação inferior da tolerância dividida pela dispersão superior real do processo, equação 13.

$$
C P L=\frac{\overline{\bar{X}}-L I E}{3 \hat{\sigma}_{S}}
$$

- $\quad$ Capabilidade (Cpk): é o índice que leva em conta a centralização do processo e é definido como o mínimo entre CPU e CPL.

\subsubsection{Outras ferramentas do CEP}

Além dos gráficos de controle, O CEP se utiliza de outras ferramentas 
estatísticas úteis, dentre as quais destaca-se:

- Histograma - permite verificar a forma da distribuição, a média e a dispersão dos dados;

- Diagrama de causa e efeito - figura composta de linhas e símbolos, representando uma relação significativa entre um efeito e suas possíveis causas.

- Diagrama de Pareto - tem como base o princípio de que "as coisas mais importantes, em primeiro lugar". É usado quando é preciso dar atenção aos problemas de uma maneira sistemática e também quando se tem um grande número de problemas e recursos limitados para resolvê-los. O diagrama indica as áreas mais problemáticas, seguindo uma ordem de prioridade.

- Gráfico linear - é uma representação dos dados, na ordem em que estes foram obtidos. Assim, é possível verificar se há presença de alguma tendência ao longo do tempo.

- $\quad$ Diagrama de dispersão - Quando duas ou mais variáveis apresentam uma tendência de variação conjunta. Ou seja, quando o valor de uma se altera, o da outra também se altera, diz-se que estas estão relacionadas. 


\section{MATERIAIS E MÉTODOS}

Embora o objeto da pesquisa sejam calços de motor com diâmetro $\varnothing 33 \mathrm{~mm}$, utilizou-se para o estudo peças com diâmetro $\varnothing 15,00 \mathrm{~mm}$. Essa alteração no projeto fez-se necessário em função da indisponibilidade do equipamento originalmente proposto. Contudo, não houve prejuízo nos resultados finais pois, a única variável estudada foi a altura.

O alcance dos objetivos requer que $\mathrm{O}$ trabalho executado duas etapas. A primeira está relacionada à metalurgia do pó (preparação da mistura de pós, a compactação e a sinterização). A Fig. 15 mostra o fluxo do processo na obtenção das peças, objeto deste estudo. A segunda refere-se ao tratamento estatístico, com o material na condição a verde e após sinterização.

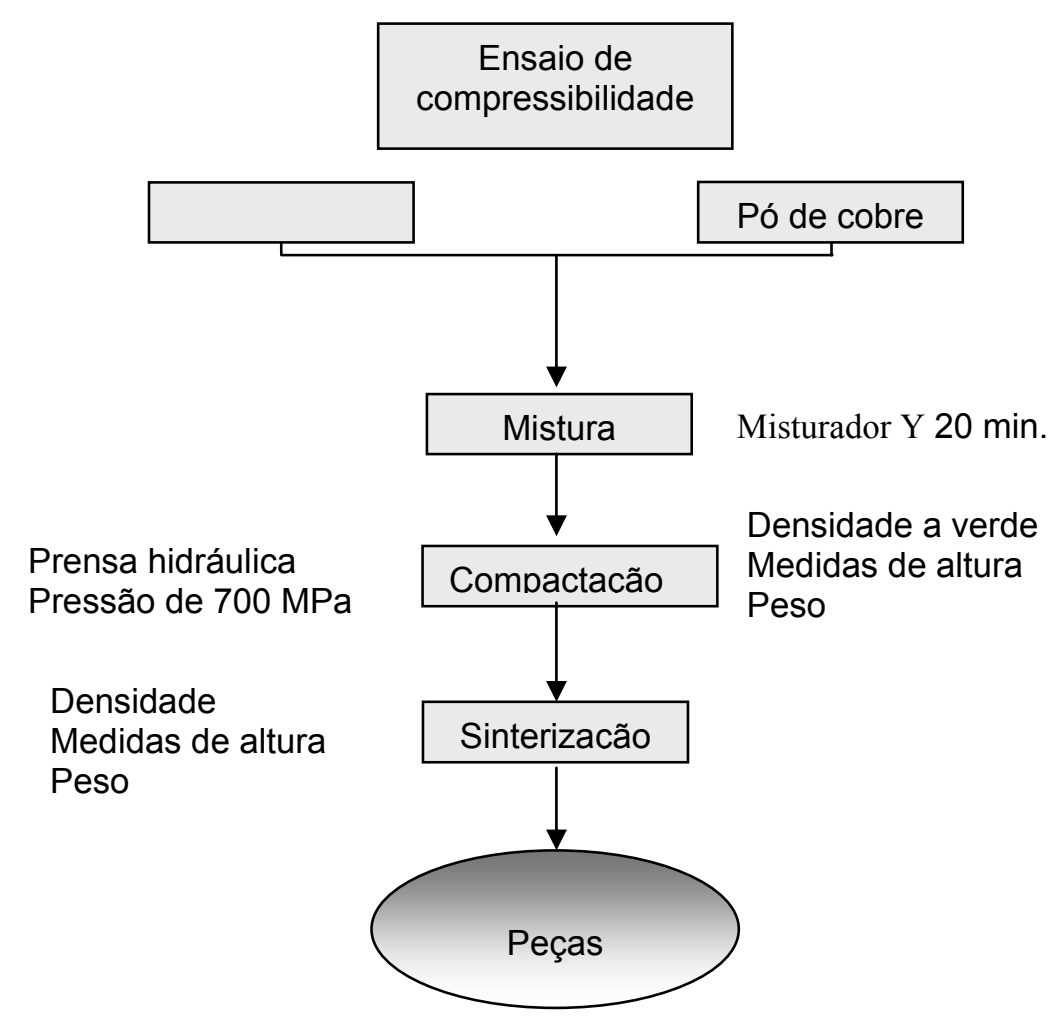

Figura 15. Fluxo do processo da metalurgia do pó.

\subsection{Materiais}

Para a fabricação das peças foi utilizado como material-base o pó de ferro puro atomizado e reduzido, ASC100.29 - Comercial - SAE 1045, aço com 0,45\% de 
carbono em massa, fabricado pela Höganäs. As Tabs. 2, 3 e 4 apresentam as características do pó. Com a finalidade de manter o teor de carbono final em 0,45\% em massa, foram realizadas adições de carbono, caracterizado como Micrograf 9925MP ML - SC 15 PI. Esse material foi fornecido pela Nacional Grafite Ltda., vide Tabs. 5, 6 e 7. Na composição da liga foi utilizado, também, Cobre PAC fD.2200.017 fornecido pela Metalpó Indústria e Comércio Ltda., Tab. 8. Durante a prensagem identificou-se a necessidade de se adicionar $1 \%$ em massa o lubrificante Licowax.

\subsection{Caracterização dos pós}

Tabela 2. Propriedades físicas do pó de ferro ASC 100.29.

\begin{tabular}{lllll}
\hline & Unidade & Mínimo & Máximo & Resultado \\
\hline Densidade aparente & $\mathrm{g} / \mathrm{cm}^{3}$ & 2,88 & 3,03 & 2,940 \\
\hline Escoamento & $\mathrm{S} / 50 \mathrm{~g}$ & $\ldots$ & 28,0 & 25,1 \\
\hline Compressibilidade a $600 \mathrm{Mpa}$ & 7,16 & $\ldots$ & 7,17 & \\
\hline
\end{tabular}

... Não especificado.

Tabela 3. Composição química do pó de ferro (\% em massa) ASC 100.29.

\begin{tabular}{lllll}
\hline & Unidade & Mínimo & Máximo & Resultado \\
\hline Carbono $(\mathrm{C})$ & $\%$ & $\ldots$ & 0,010 & 0,001 \\
\hline O - TOT & $\%$ & $\ldots$ & 0,11 & 0,100 \\
\hline
\end{tabular}

... Não especificado.

Tabela 4. Granulometria do pó de ferro ASC 100.29.

\begin{tabular}{lllll}
\hline & Unidade & Mínimo & Máximo & Resultado \\
\hline + Malha $80(0,180 \mathrm{~mm})$ & $\%$ & - & 2,0 & 0,700 \\
\hline $\begin{array}{l}\text { + Malha } 100(0,150 \mathrm{~mm})-\text { Malha } 70 \\
(0,212 \mathrm{~mm})\end{array}$ & $\%$ & - & 12,0 & 5,900 \\
\hline + Malha $325(0,045 \mathrm{~mm})$ & - & 15,0 & 30,0 & 24,700 \\
\hline
\end{tabular}

Tabela 5. Análise química e termodinâmica do pó de grafite - Micrograf 9925 MP ML - SC 15 PL.

\begin{tabular}{l|l|l|l|l}
\hline & Unidade & Encontrado & $\begin{array}{l}\text { Especificado } \\
\text { mínimo }\end{array}$ & $\begin{array}{l}\text { Especificado } \\
\text { máximo }\end{array}$ \\
\hline Carbono (perda ao fogo) & $\%$ & 99,93 & 99,00 & 100,00 \\
\hline Cinzas & $\%$ & 0,07 & 0,00 & 1,00 \\
\hline
\end{tabular}


Tabela 6. Análise física do pó de grafite - Micrograf 9925 MP ML - SC 15 PL.

\begin{tabular}{lllll}
\hline & Unidade & Encontrado & $\begin{array}{l}\text { Especificado } \\
\text { mínimo }\end{array}$ & $\begin{array}{l}\text { Especificado } \\
\text { máximo }\end{array}$ \\
\hline $325 \#(45 \mu \mathrm{m})$ & $\%$ ret. acum. & 3,73 & 0,00 & 5,00 \\
\hline Densidade Scott & $\mathrm{g} / \mathrm{in}^{3}$ & 3,47 & 3,30 & 4,00 \\
\hline
\end{tabular}

Tabela 7. Análise física do pó de cobre PAC - D.2200.017.

\begin{tabular}{llll}
\hline \multirow{2}{*}{ Características } & Especificado & & \multirow{2}{*}{ Encontrado } \\
\cline { 2 - 3 } & Mínimo & Máximo & \\
\hline Densidade aparente $\left(\mathrm{g} / \mathrm{cm}^{3}\right)$ & 2,50 & 3,00 & 2,84 \\
\hline Malha +325 & & 10,00 & 5,36 \\
\hline Malha -325 & 90,0 & & 94,64 \\
\hline
\end{tabular}

\subsection{Análise da compressibilidade}

Com o objetivo de se analisar compressibilidade do material foram realizados ensaios de compressibilidade, obtendo-se os resultados mostrados na Fig. 16. As amostras foram compactadas até a pressão de $390 \mathrm{MPa}$, que é a pressão máxima permitida pela matriz de compactação. Isto dá uma massa específica a verde de $6,76 \mathrm{~g} / \mathrm{cm}^{3}$ ou um $86,6 \%$ da densidade teórica, indicando a boa compressibilidade do pó.

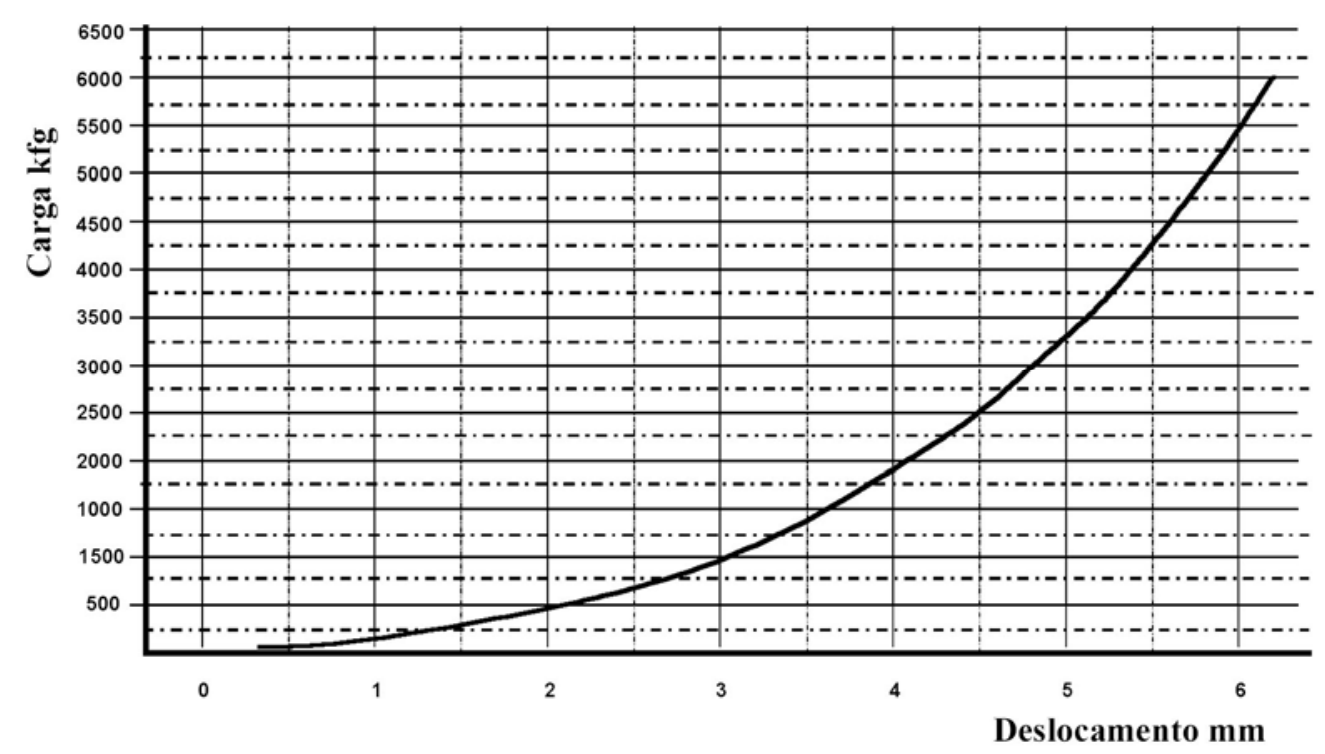

Figura 16. Gráfico de carga versus deslocamento obtido na compressibilidade do pó de ferro ASC 100.29. 


\subsection{O processo}

O processamento do material se iniciou pela mistura da matéria-prima na proporção em massa de $0,5 \%$ de grafite, 2,0\% de cobre e balanço em pó de ferro. Para misturar e homogeneizar o material é utilizado um misturador em $\mathrm{Y}$, por 20 minutos, Fig. 17. Durante o processo foi necessário adicionar o lubrificante Licowax em $1,0 \%$ em peso.

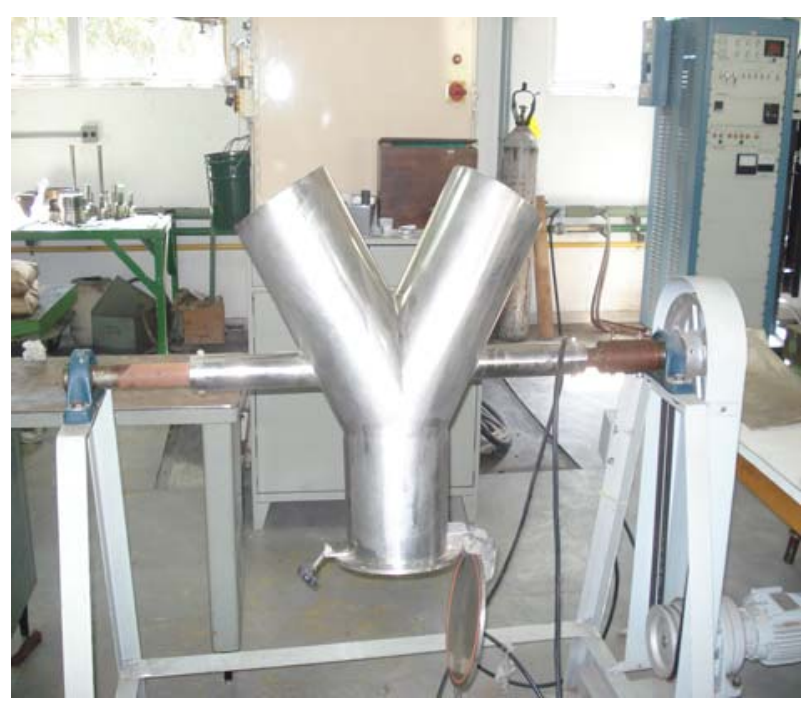

Figura 17. Misturador tipo $\mathrm{Y}$ utilizado nos experimentos.

A seguir o material está foi compactado em uma prensa hidráulica Silme, Fig. 18, a uma pressão de $400 \mathrm{MPa}$. As peças foram compactadas na empresa Brats Indústria e Comércio de Produtos Metálicos Especiais, localizada no município de Cajamar - SP

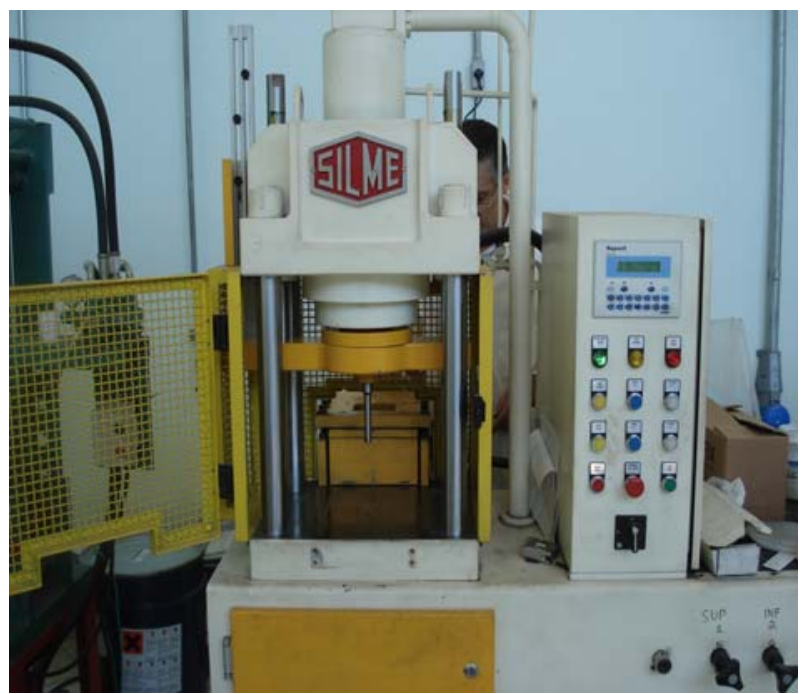

Figura 18. Prensa hidráulica instrumentada Silme usada na compactação das amostras. 
O início da compactação, requereu o ajuste da profundidade da cavidade de enchimento através de testes até tornar possível alcançar a medida ideal para a produção do primeiro lote. A cada lote a ser produzido, novos testes foram requeridos obtendo as profundidades ideais para cada altura das peças. Vide Tab.8

Tabela 8. Relação da profundidade da cavidade com a altura da peça a verde.

\begin{tabular}{|c|c|}
\hline $\begin{array}{l}\text { Profundidade da } \\
\text { cavidade }(\mathrm{mm})\end{array}$ & Altura $(\mathrm{mm})$ \\
\hline 5,55 & 3,00 \\
\hline 5,56 & 3,10 \\
\hline 5,89 & 3,20 \\
\hline 6,14 & 3,30 \\
\hline 6,27 & 3,40 \\
\hline 6,71 & 3,60 \\
\hline
\end{tabular}

Por meio de análise de regressão linear ajustou-se uma equação que relaciona a profundidade com a altura do produto final, equação. Dessa forma é possível rapidamente calcular a cavidade desejada, gerando grande economia de tempo.

$a=y-b x$ onde $b=s x y / s x^{2}$

$b=0,41 x$ e $a=0,785$ onde: $y=$ altura da peça

$\mathrm{x}=$ profundidade

Assim, foram obtidas as 1800 peças a serem estudadas. A seguir, agrupadas em 6 lotes de 300 peças, numeradas, medidas e pesadas.

\subsection{O tratamento estatístico}

O tratamento estatístico teve início na definição da amostra. A amostra, correspondente ao subgrupo, foi definida pelo conjunto de peças retiradas da produção em determinado período de tempo, aleatoriamente, de forma que fosse representativa de toda a produção no período.

Não existe uma regra para definir o tamanho do subgrupo e o número de subgrupos para se construir uma carta de controle. No entanto julgou-se necessário a formação de 30 amostras $(\mathrm{K})$ de tamanho $(\mathrm{n})$ igual 10 para classes, cujos dados 
estão disponibilizados nos anexos deste trabalho.

O passo seguinte foi a coleta dos dados, quando as peças foram identificadas pesadas e medidas as alturas, individualmente. Utilizando-se das ferramentas disponibilizadas no programa Excel, os dados foram planilhados e extraídas as informações preliminares, cujo resumo está apresentado na Tab. 9.

Tabela 9. Resumo dos dados coletados

\begin{tabular}{rrrccc}
\hline $\begin{array}{l}\text { Altura } \\
\text { nominal }\end{array}$ & $\begin{array}{l}\text { Altura } \\
\text { média }\end{array}$ & $\begin{array}{l}\text { Desvio } \\
\text { padrão }\end{array}$ & $\begin{array}{l}\text { Densidade } \\
\text { nominal } \\
\mathrm{g} / \mathrm{cm}^{3}\end{array}$ & $\begin{array}{l}\text { Densidade } \\
\text { aparente } \\
\mathrm{g} / \mathrm{cm}^{3}\end{array}$ & $\begin{array}{l}\text { Desvio } \\
\text { padrão } \\
\text { densidade }\end{array}$ \\
\hline 3,000 & 3,008 & 0,015 & 6,76 & 6,86 & 0,014 \\
\hline 3,100 & 3,059 & 0,011 & 6,76 & 6,88 & 0,032 \\
\hline 3,200 & 3,167 & 0,009 & 6,76 & 6,83 & 0,025 \\
\hline 3,300 & 3,328 & 0,011 & 6,76 & 6,83 & 0,045 \\
\hline 3,400 & 3,433 & 0,016 & 6,76 & 6,80 & 0,355 \\
\hline 3,500 & 3,607 & 0,012 & 6,76 & 6,85 & 0,396 \\
\hline
\end{tabular}

\subsubsection{Montagem dos gráficos de controle}

Para a elaboração dos gráficos de controle foi utilizado o mesmo programa Excel. Esse programa tem a vantagem de além de ser planilha de cálculo, em seu módulo de gráfico permite se montar os gráficos utilizados neste trabalho: gráficos de controle e histograma.

Os gráficos foram selecionados em função do tamanho da amostra $n>10$ (30), foi selecionado a carta de controle por variáveis, e dentro destes, de acordo com o tamanho das amostras forma considerados adequados os gráficos $\mathrm{X}$ barra e $\mathrm{s}$. 


\section{RESULTADOS E DISCUSSÃO}

A apresentação dos dados se dá na forma de gráficos que além do apelo visual têm a vantagem de mostrar com maio clareza tendências e comparações. Os resultados são apresentados individualmente, tendo $\mathrm{m}$ vista que como dessa forma será possível analisar o comportamento do mesmo processo em 6 momentos diferentes, pois para cada enchimento requereu um novo ajuste na prensa.

\subsection{Distribuição de freqüência por classe $-3,00$}

Nessa amostra observa-se que a altura média obtida está próxima a altura nominal de 3,00 $\mathrm{mm}$. Porém, o processo não apresentou estabilidade, com muitos pontos fora dos limites de controle e somente cinco pontos próximos da linha média. vide Fig. 19. A causa para esse resultado, pode ser atribuída pela estreita faixa dos limites de controle, indicando, falsamente, muitas causas especiais a serem analisadas.

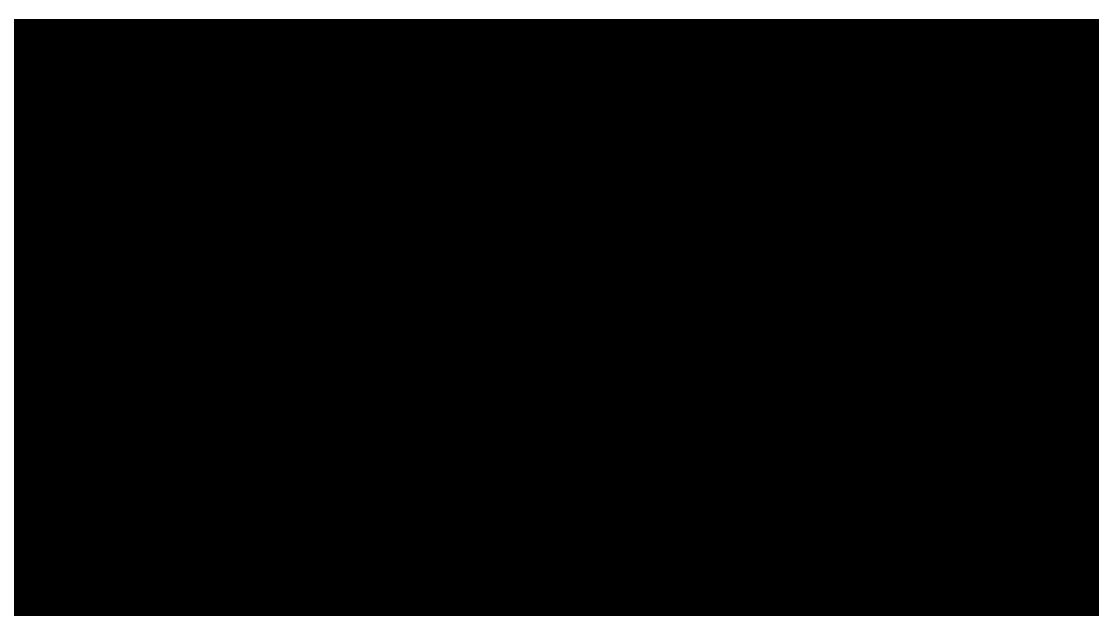

Figura 19. Carta de controle da média classe 3,00.

No gráfico carta de controle de dispersão (Fig. 20) observa-se que embora todos os pontos estejam dentro dos limites de controle, o processo evidência a presença de tendências nos pontos com 9 pontos consecutivos do mesmo lado da linha média. 


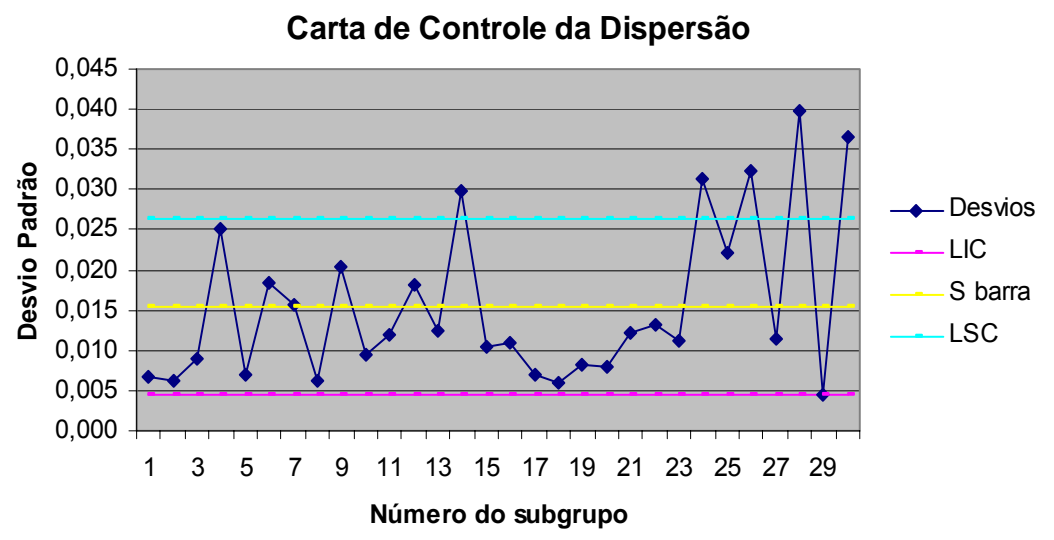

Figura 20. Carta de controle da dispersão classe 3,00.

O histograma tipo bimodal, Fig. 21, evidencia uma freqüência baixa próximo ao meio da amplitude de dados com um pico em cada lado.

Tabela 10. Distribuição de freqüência por classe 3,00.

\begin{tabular}{|c|c|c|c|c|c|}
\hline \multicolumn{3}{|c|}{ Classes } & \multicolumn{2}{|c|}{ Freqüência \% } & \multirow{2}{*}{$\frac{\% \text { Acumulada }}{0,3 \%}$} \\
\hline 1 & 2,927 & 2,944 & 1 & $0,3 \%$ & \\
\hline 2 & 2,944 & 2,960 & 2 & $0,7 \%$ & $1,0 \%$ \\
\hline 3 & 2,960 & 2,977 & 19 & $6,3 \%$ & $7,3 \%$ \\
\hline 4 & 2,977 & 2,993 & 56 & $18,7 \%$ & $26,0 \%$ \\
\hline 5 & 2,993 & 3,010 & 56 & $18,7 \%$ & $44,7 \%$ \\
\hline 6 & 3,010 & 3,026 & 37 & $12,3 \%$ & $57,0 \%$ \\
\hline 7 & 3,026 & 3,043 & 60 & $20,0 \%$ & $77,0 \%$ \\
\hline 8 & 3,043 & 3,059 & 52 & $17,3 \%$ & $94,3 \%$ \\
\hline \multirow[t]{2}{*}{9} & 3,059 & 3,076 & 17 & $5,7 \%$ & $100,0 \%$ \\
\hline & Total & & 300 & & \\
\hline
\end{tabular}


Histograma

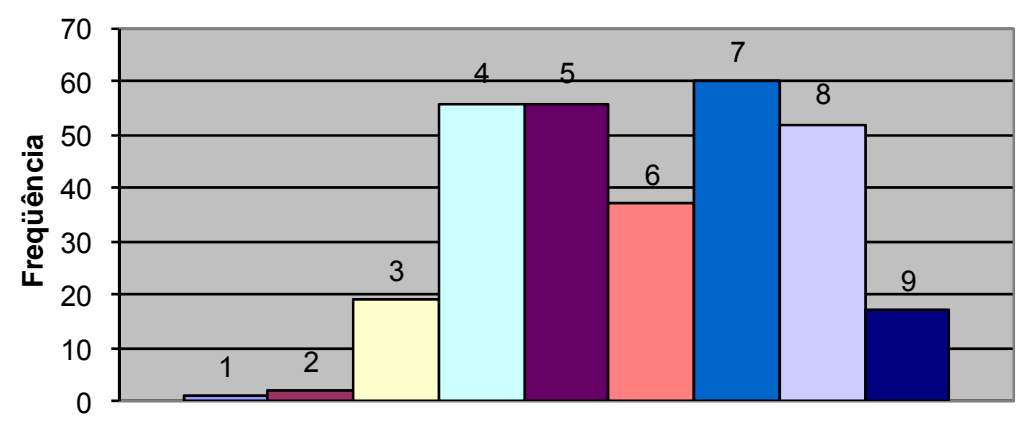

Figura 21. Histograma classe 3,00.

\subsection{Distribuição de freqüência por classe - 3,10}

Quanto a essa amostra, a exemplo da anterior a altura média, 3,06 mm está abaixo da altura nominal 3,10 mm. Através da análise gráfica (Fig. 22), percebe-se que o processo se comportou estável com todos os pontos dentro dos limites de controle e bem distribuídos. A mesma estabilidade se observa na carta de controle da dispersão (Fig. 23), quando indica que a maioria dos pontos situam próximos à linha média. Somente dois pontos forma encontrados nos limites de controle.

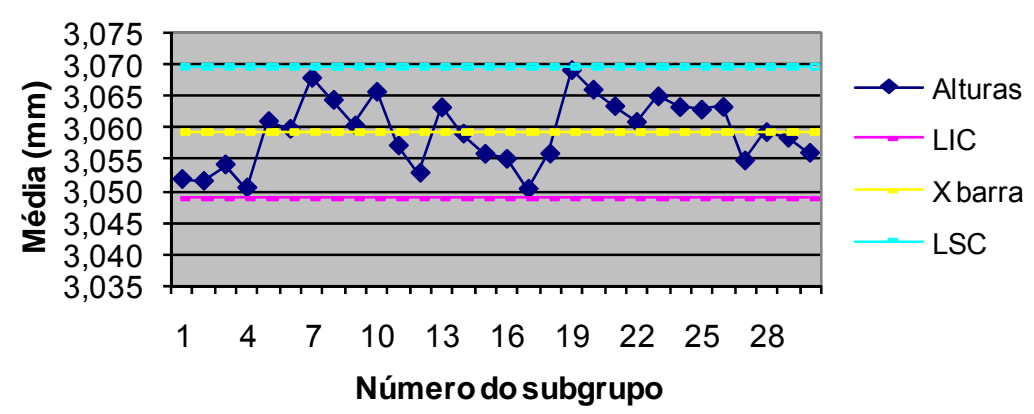

Figura 22. Carta de controle da média classe 3,10. 


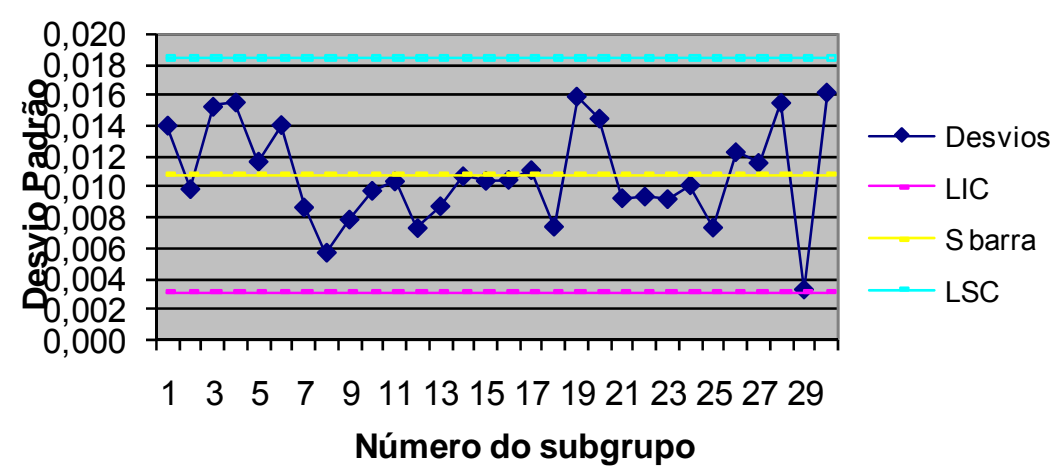

Figura 23. Carta de controle da dispersão classe 3,10.

Tabela 11. Distribuição de freqüência por classe 3,10.

\begin{tabular}{cccccc}
\hline \multicolumn{2}{l}{ Classes } & \multicolumn{3}{c}{ Freqüência $\%$} & \% Acumulada \\
\hline 1 & 3,027 & 3,035 & 8 & $2,7 \%$ & $2,7 \%$ \\
\hline 2 & 3,035 & 3,043 & 20 & $6,7 \%$ & $9,3 \%$ \\
\hline 3 & 3,043 & 3,052 & 62 & $20,7 \%$ & $30,0 \%$ \\
\hline 4 & 3,052 & 3,060 & 75 & $25,0 \%$ & $55,0 \%$ \\
\hline 5 & 3,060 & 3,069 & 79 & $26,3 \%$ & $81,3 \%$ \\
\hline 6 & 3,069 & 3,077 & 36 & $12,0 \%$ & $93,3 \%$ \\
\hline 7 & 3,077 & 3,085 & 19 & $6,3 \%$ & $99,7 \%$ \\
\hline 8 & 3,085 & 3,094 & 0 & $0,0 \%$ & $99,7 \%$ \\
\hline 9 & 3,094 & 3,102 & 1 & $0,3 \%$ & $100,0 \%$ \\
\hline & Total & 300 & & \\
\hline
\end{tabular}

O histograma do tipo normal (Fig. 24) indica que o valor meio do histograma fica localizado à esquerda do centro da amplitude. A freqüência decresce mais acentuadamente em direção dão lado direito. 


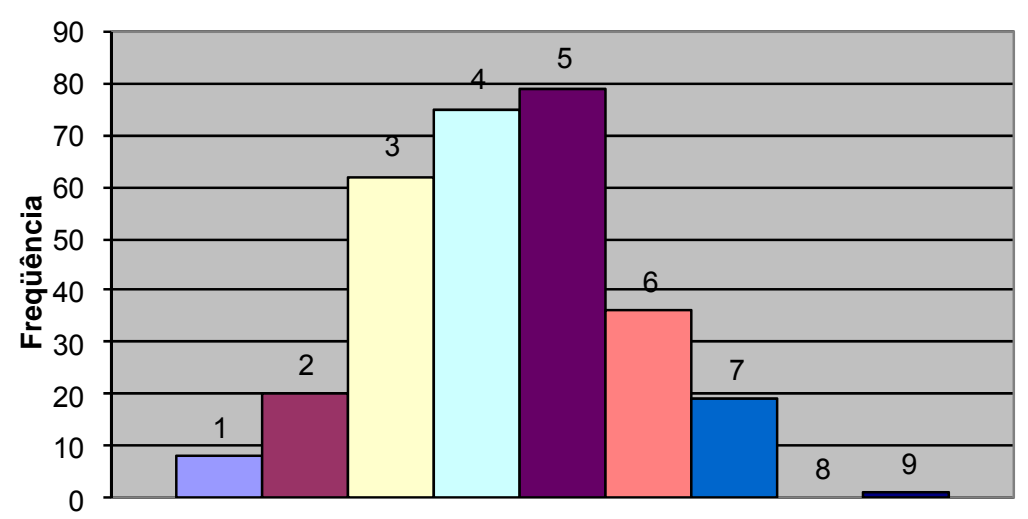

Figura 24. Histograma classe 3,10.

\subsection{Distribuição de freqüência por classe $-3,20$}

Para essa classe, a média de altura se situou abaixo da altura nominal, indicando a necessidade de um pequeno ajuste na máquina. Quanto a distribuição dos pontos na carta de controle da média - Fig. 25, há a indicação de que o processo é estável, porém, mas observamos uma ampla dispersão.

\section{Carta de Controle da Média - X barra}

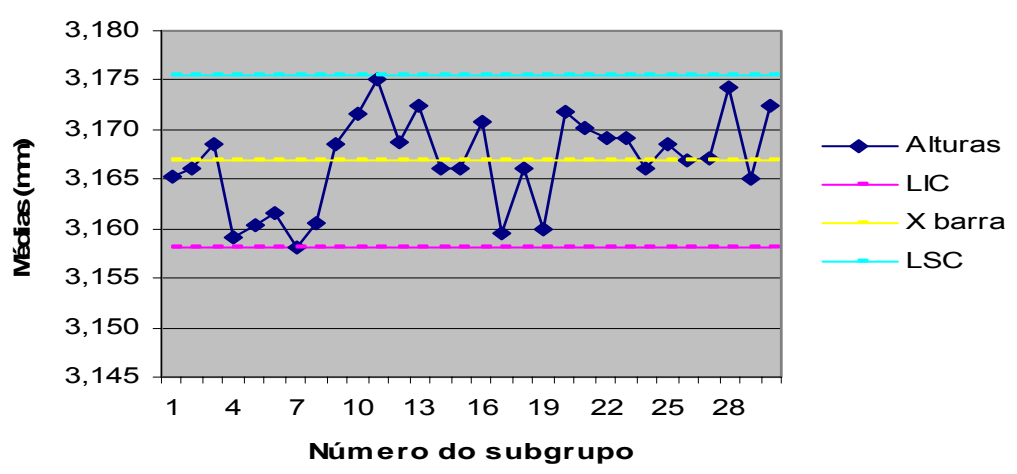

Figura 25. Carta de controle da média classe 3,20.

Por outro lado, a carta de controle da dispersão Fig. 26, ponta para um processo estável por apresentar uma distribuição balanceada dos pontos, abaixo e acima do valor central. 


\section{Carta de Controle da Dispersão}

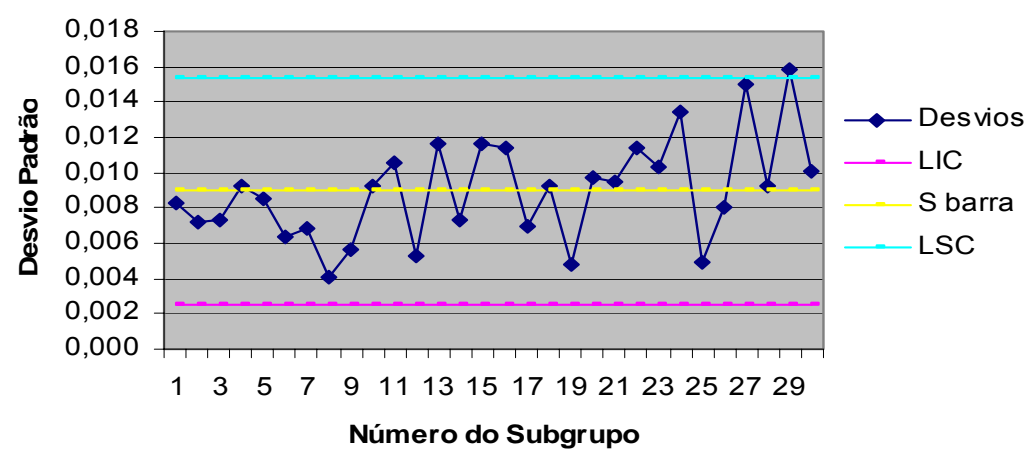

rigura 26 . Larta de controle da aispersao classe $3,2 U$.

O histograma Fig. 27 evidencia, por sua forma normal, que o processo é estável .Neste caso a freqüência é mais alta no meio e torna-se mais baixa nas duas direções.

Tabela 12. Distribuição de freqüência por classe 3,20.

\begin{tabular}{cccccc}
\hline \multicolumn{2}{l}{ Classes } & \multicolumn{3}{c}{ Freqüência $\%$} & $\begin{array}{l}\text { \% } \\
\text { Acumulada }\end{array}$ \\
\hline 1 & 3,138 & 3,144 & 4 & $1,3 \%$ & $1,3 \%$ \\
\hline 2 & 3,144 & 3,150 & 6 & $2,0 \%$ & $3,3 \%$ \\
\hline 3 & 3,150 & 3,156 & 34 & $11,3 \%$ & $14,7 \%$ \\
\hline 4 & 3,156 & 3,162 & 61 & $20,3 \%$ & $35,0 \%$ \\
\hline 5 & 3,162 & 3,168 & 73 & $24,3 \%$ & $59,3 \%$ \\
\hline 6 & 3,168 & 3,174 & 57 & $19,0 \%$ & $78,3 \%$ \\
\hline 7 & 3,174 & 3,180 & 38 & $12,7 \%$ & $91,0 \%$ \\
\hline 8 & 3,180 & 3,186 & 17 & $5,7 \%$ & $96,7 \%$ \\
\hline 9 & 3,186 & 3,192 & 10 & $3,3 \%$ & $100,0 \%$ \\
\hline & Total & 300 & & \\
\hline \multicolumn{7}{c}{30}
\end{tabular}




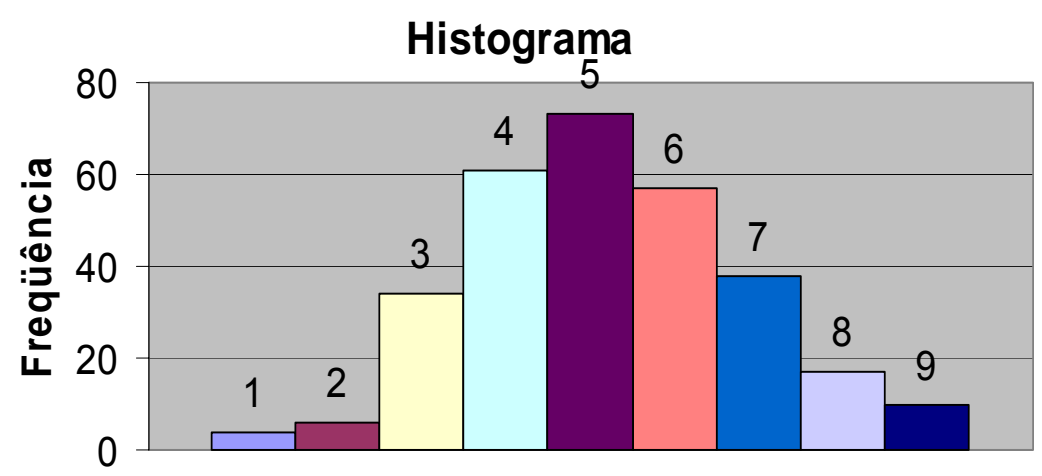

Figura 27. Histograma classe 3,20.

\subsection{Distribuição de freqüência por classe - 3,30}

Neste caso a média das alturas se posicionou acima da altura nominal. Como já descrito, essa pequena diferença requer pequenos ajustes na prensa. Quanto a analise de estabilidade do processo, a Fig. 28 torna evidente que naquele momento o processo se mostrou instável, com muitos pontos assinaláveis, sugerindo a necessidade de se verificar se são causas especiais ou aleatórias. Nesses casos, requerendo ajustes no processo, ou na amostra. Quanto a dispersão, o gráfico Fig. 29, também aponta para a existência de tendência com vários ponto de um mesmo lado da linha média.

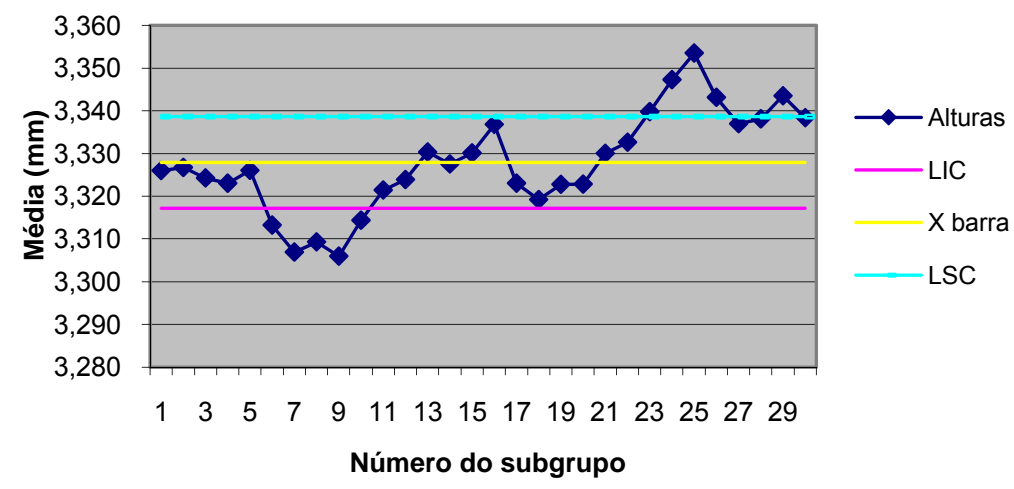

Figura 28. Carta de controle da média classe 3,30. 


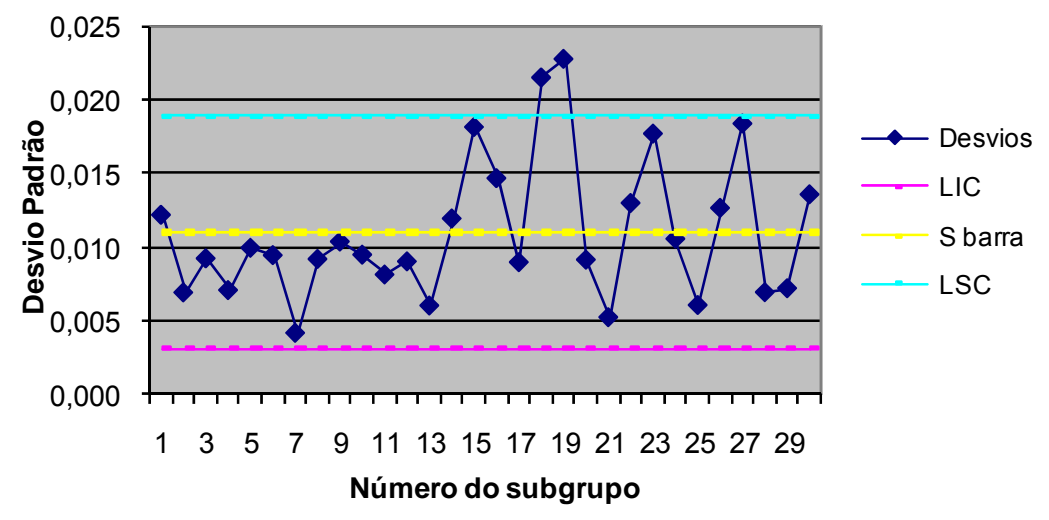

Figura 29. Carta de controle da dispersão classe 3,30.

Tabela 13. Distribuição de freqüência por classe 3,30.

\begin{tabular}{cccccc}
\hline \multicolumn{2}{l}{ Classes } & \multicolumn{3}{c}{ Freqüência $\%$} & \% Acumulada \\
\hline 1 & 3,263 & 3,274 & 1 & $0,3 \%$ & $0,3 \%$ \\
\hline 2 & 3,274 & 3,286 & 0 & $0,0 \%$ & $0,3 \%$ \\
\hline 3 & 3,286 & 3,298 & 7 & $2,3 \%$ & $2,7 \%$ \\
\hline 4 & 3,298 & 3,309 & 32 & $10,7 \%$ & $13,3 \%$ \\
\hline 5 & 3,309 & 3,321 & 61 & $20,3 \%$ & $33,7 \%$ \\
\hline 6 & 3,321 & 3,332 & 86 & $28,7 \%$ & $62,3 \%$ \\
\hline 7 & 3,332 & 3,344 & 67 & $22,3 \%$ & $84,7 \%$ \\
\hline 8 & 3,344 & 3,356 & 33 & $11,0 \%$ & $95,7 \%$ \\
\hline 9 & 3,356 & 3,367 & 13 & $4,3 \%$ & $100,0 \%$ \\
\hline & Total & 300 & & \\
\hline 76
\end{tabular}

Embora as cartas de controle demonstrem instabilidade no processo, o histograma. Fig. 30 apresenta uma distribuição normal. Embora deslocado á direita, indica que o processo pode ser ajustado, por apresentar uma regularidade. 


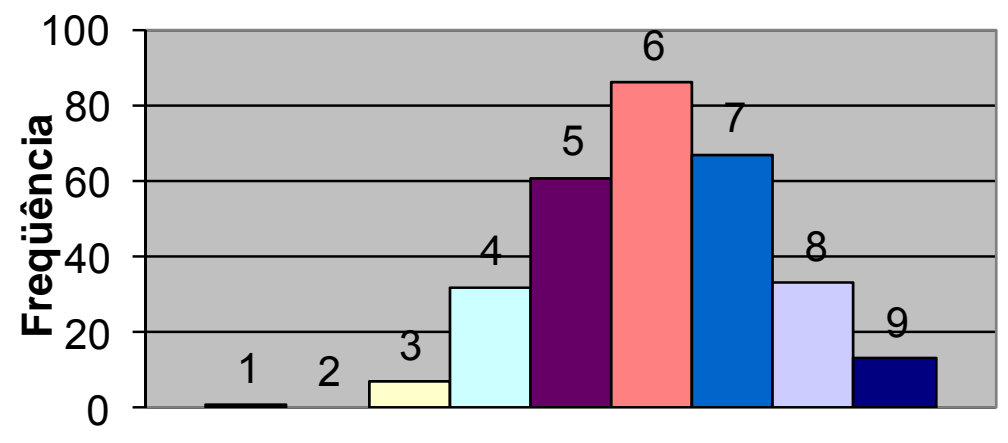

Figura 30. Histograma classe 3,30.

\subsection{Distribuição de freqüência por classe - 3,40}

As cartas de controle da média (Fig. 31) e a de controle da dispersão (Fig. 32), apontam e para uma estabilidade dos processo, por apresentar poucos pontos próximos aos limites.

Carta de Controle da Média - X barra

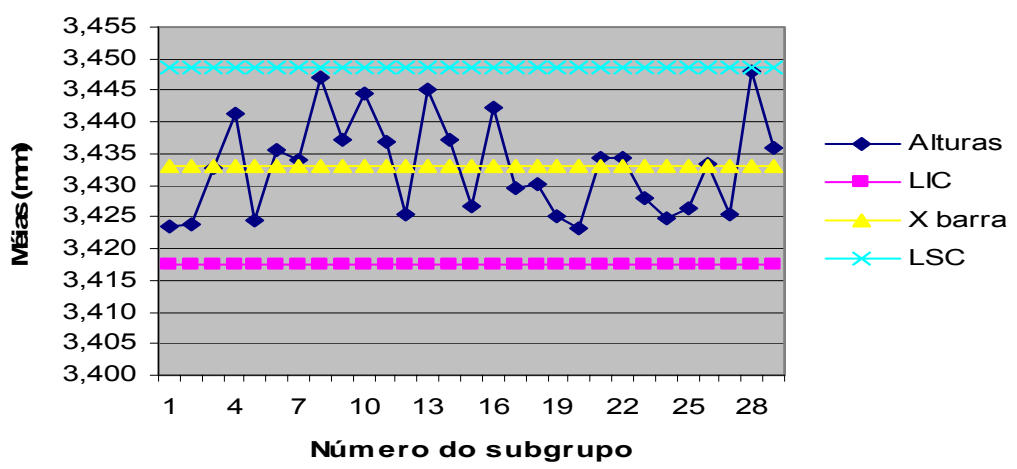

Figura 31. Carta de controle da média classe 3,40. 


\section{Carta de Controle da Dispersão}

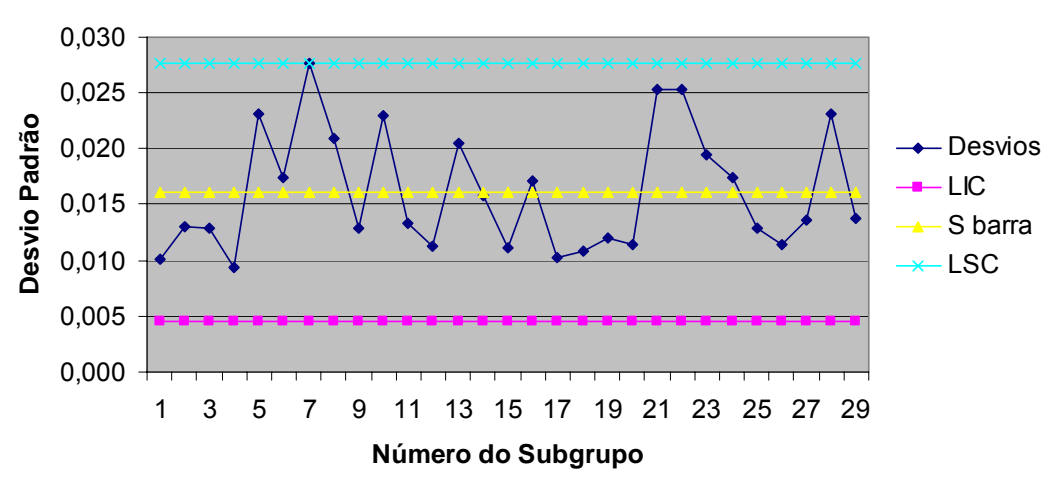

Figura 32. Carta de controle da dispersão classe 3,40.

Tabela 14. Distribuição de freqüência por classe 3,40.

\begin{tabular}{cccccc}
\hline \multicolumn{2}{l}{ Classes } & & Freqüência & $\%$ & $\begin{array}{c}\% \\
\text { Acumulada }\end{array}$ \\
\hline 1 & 3,372 & 3,387 & 4 & $1,4 \%$ & $1,4 \%$ \\
\hline 2 & 3,387 & 3,401 & 6 & $2,1 \%$ & $3,5 \%$ \\
\hline 3 & 3,401 & 3,415 & 31 & $10,7 \%$ & $14,2 \%$ \\
\hline 4 & 3,415 & 3,430 & 87 & $30,1 \%$ & $44,3 \%$ \\
\hline 5 & 3,430 & 3,444 & 97 & $33,6 \%$ & $77,9 \%$ \\
\hline 6 & 3,444 & 3,458 & 47 & $16,3 \%$ & $94,1 \%$ \\
\hline 7 & 3,458 & 3,473 & 11 & $3,8 \%$ & $97,9 \%$ \\
\hline 8 & 3,473 & 3,487 & 3 & $1,0 \%$ & $99,0 \%$ \\
\hline 9 & 3,487 & 3,501 & 3 & $1,0 \%$ & $100,0 \%$ \\
\hline & Total & 289 & & & \\
\hline
\end{tabular}

O histograma, Fig. 33 demonstra uma distribuição normal, com valor médio no meio da amplitude de dados. Indicando que o processo está estável. Essa é a indicação de que não existem restrições para os valores que podem ser assumidos. 


\section{Histograma}

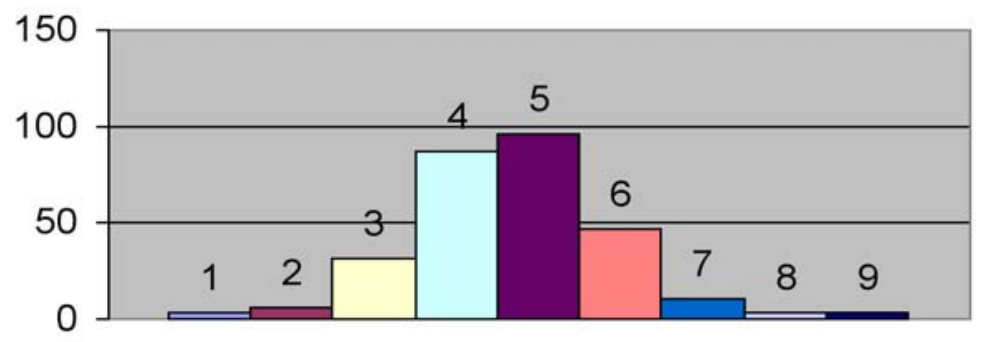

Figura 33. Histograma classe 3,40.

\subsection{Distribuição de freqüência por classe - 3,60}

O processo de produção da peça classe 3,60 foi a que apresentou o maior número de pontos fora do limites de controle exigindo ajuste nos dados das cartas de controle. Esses ajustes geram os chamados limites de controle revisado, dessa forma, se observa através da carta de controle da média Fig. 34. Mesmo assim, nota-se alguns pontos fora dos limites de controle.

Carta de Controle da Média - X barra

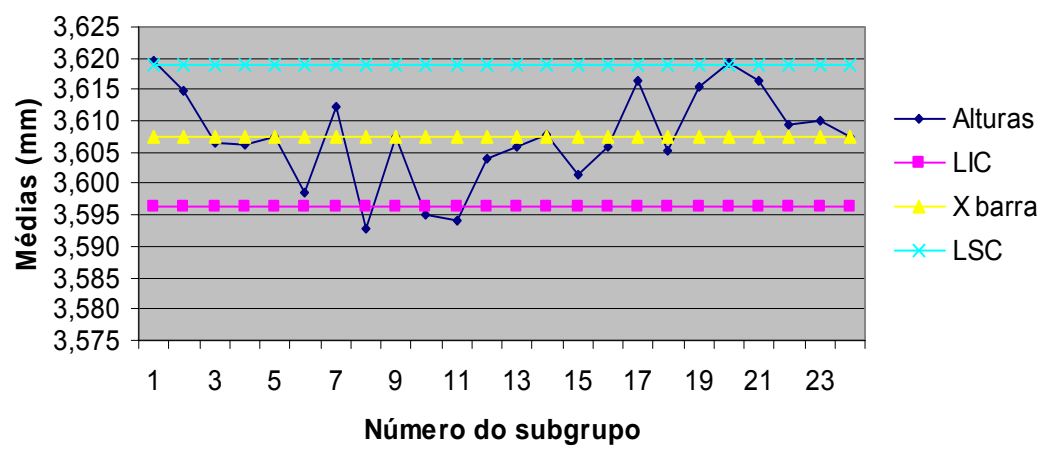

Figura 34. Carta de controle da média classe 3,60.

Ao analisar-se a carta de controle da dispersão (Fig. 35), constata-se que não há variação significativa pois o gráfico demonstra que todos os pontos estão bem distribuídos entre as linhas de controle. 
Carta de Controle da Dispersão

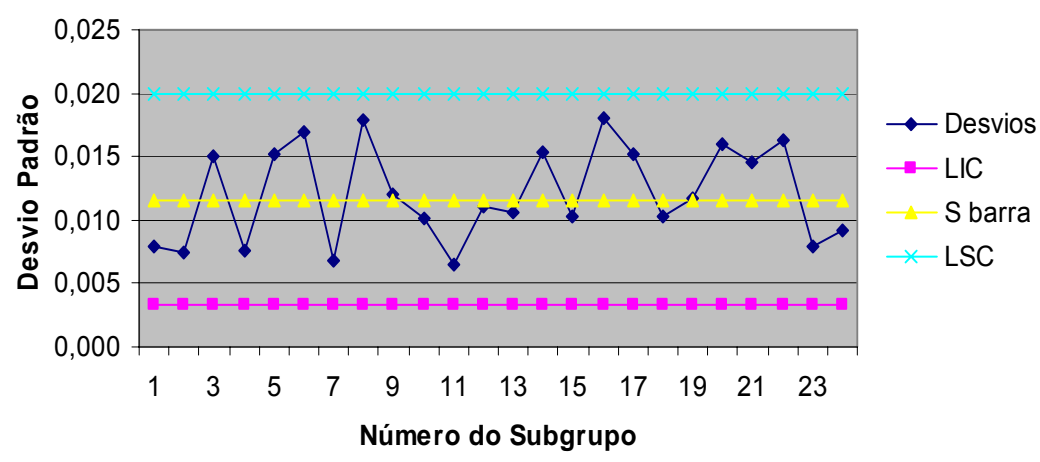

Figura 35. Carta de controle da dispersão classe 3,60.

Tabela 15. Distribuição de freqüência por classe 3,60.

\begin{tabular}{cccccc}
\hline \multicolumn{2}{l}{ Classes } & \multicolumn{3}{c}{ Freqüência $\%$} & \% Acumulada \\
\hline 1 & 3,562 & 3,572 & 3 & $1,3 \%$ & $1,3 \%$ \\
\hline 2 & 3,572 & 3,581 & 6 & $2,6 \%$ & $3,9 \%$ \\
\hline 3 & 3,581 & 3,590 & 15 & $6,5 \%$ & $10,3 \%$ \\
\hline 4 & 3,590 & 3,599 & 44 & $19,0 \%$ & $29,3 \%$ \\
\hline 5 & 3,599 & 3,609 & 51 & $22,0 \%$ & $51,3 \%$ \\
\hline 6 & 3,609 & 3,618 & 62 & $26,7 \%$ & $78,0 \%$ \\
\hline 7 & 3,618 & 3,627 & 39 & $16,8 \%$ & $94,8 \%$ \\
\hline 8 & 3,627 & 3,637 & 10 & $4,3 \%$ & $99,1 \%$ \\
\hline 9 & 3,637 & 3,646 & 2 & $0,9 \%$ & $100,0 \%$ \\
\hline & Total & \multicolumn{5}{c}{232} \\
\hline
\end{tabular}

O histograma (Fig. 36), é do tipo assimétrico negativo, que apresenta o valor médio à direita do centro da amplitude, indicando a impossibilidade teórica de ocorrência de valores mais altas. 


\section{Histograma}

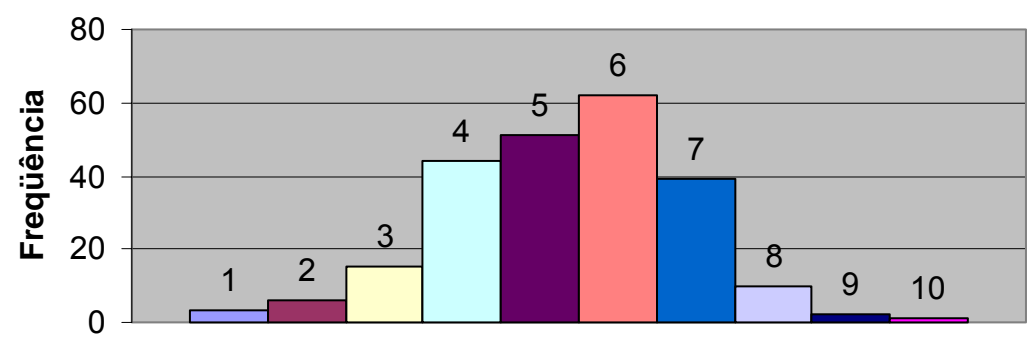

Figura 36. Histograma classe 3,60.

\subsection{Exame de capacidade de processo}

O exame de capacidade consiste na verificação do processo em atender as especificações requeridas comparando com a variação natural do processo. Isso é possível través do cálculo dos índices de capabilidade do processo.

Tabela 16. Índice de capacidade do processo.

\begin{tabular}{lllll}
\hline Classe & \multirow{2}{*}{ LSE } & \multirow{2}{*}{ LIE } & $\begin{array}{l}\text { Desvio padrão } \\
\text { do processo }\end{array}$ & CP \\
\hline 3,050 & 3,070 & 3,030 & 0,015 & 0,43 \\
\hline 3,100 & 3,120 & 3,080 & 0,011 & 0,59 \\
\hline 3,200 & 3,220 & 3,180 & 0,009 & 0,72 \\
\hline 3,300 & 3,320 & 3,280 & 0,011 & 0,59 \\
\hline 3,400 & 3,420 & 3,380 & 0,016 & 0,41 \\
\hline 3,600 & 3,620 & 3,580 & 0,012 & 0,54 \\
\hline
\end{tabular}

LSE - Limite Superior de Especificação

LIE - Limite Inferior de Especificação

CP - Capabilidade do Processo

De acordo com os valores obtidos na Tab. 16 os valores de CP indicam que é 
necessária uma ação sobre o processo no sentido de se reduzir a variabilidade pois os índices, para todos as classes é menor que um.

Outra análise complementar resulta do cálculo do faixas características do processo - FCP, que representa a faixa de valores prevêem para a maioria dos resultados futuros do processo. Essa faixa, também chamada de faixa padrão é definida pela fórmula:

$$
\begin{aligned}
\mathrm{FCP} & =\mu \pm 3 \sigma \\
\sigma & =\text { sbarra/ } \mathrm{C}_{4} \\
\mathrm{C}_{4} & =\text { fator de correção }
\end{aligned}
$$

A Tab.17 demonstra as faixas características do processo para cada classe esperada.

Tabela 17. Faixa característica do processo.

\begin{tabular}{llll}
\hline Esperada & $\begin{array}{l}\text { Desvio Padrão do } \\
\text { Processo }\end{array}$ & $\mathrm{FCP}=\mathrm{X}$ barra +ou - 3 desvios \\
\hline 3,000 & 0,015 & 3,011 & + ou - 0,0462487 \\
\hline 3,100 & 0,011 & 3,059 & + ou - 0,0339157 \\
\hline 3,200 & 0,009 & 3,167 & + ou - 0,0277492 \\
\hline 3,300 & 0,011 & 3,328 & + ou - 0,0339157 \\
\hline 3,400 & 0,016 & 3,433 & + ou - 0,049332 \\
\hline 3,600 & 0,012 & 3,607 & + ou - 0,036999 \\
\hline
\end{tabular}




\section{CONCLUSÕES}

De acordo com a análise das cartas de controle do processo, pode-se observar que não houve uma regularidade na produção, algumas classes se encontravam fora do controle, apresentando alta variação, mesmo tendo sub-lotes nos limites de controle. Diante disto, depois de identificado o sub-lote que apresentou uma causa especial de variação, ele foi retirado, para que calculados os novos limites e verificado o novo estado em que se encontrava o processo. Em alguns casos se observou que após os ajustes, os pontos plotados mantiveram-se dentro dos limites de controle. Outros continuaram apresentando instabilidade.

A instabilidade no sistema pode ser atribuída pelas constantes paradas na produção para manutenção. Assim, as razões das causas especiais se deram em razão da fadiga do equipamento.

Quanto ao material utilizado, ao que tudo indica, foi adequado, pois apresentou uma massa média específica a verde $6,84 \mathrm{~g} / \mathrm{cm}^{3}$ ou um $86,6 \%$ da densidade teórica, indicando a boa compressibilidade do pó.

Observou-se que, por meio da regressão linear pode-se ajustar uma equação da reta onde se calcula a variável desejada e isto reduziu o tempo necessário para os ajustes da prensa para se alcançar de terminada medida. Dessa forma, houve um ganho no tempo de ajustes.

Observando, as distribuições das freqüências, conclui-se que o método é potencialmente viável, pois. Os resultados demonstram que obtendo um ajuste adequado, pode-se obter um ganho no atendimento aos limites de controle e intervalos convenientes de aproveitamento. melhorar viável. Porém, há de se observar a importância do ajuste.

Como sugestão para trabalhos futuros, pode-se relacionar os custos decorrentes de processamento e reaproveitamento de maneira a determinar quais seriam intervalos ótimos, com o objetivo para a produção, e determinação dos ajuste necessários para a obtenção dos mesmos. Tais análises devem tomar ser comparativas entre as amostras a verde e sinterizadas. 


\section{REFERÊNCIAS BIBLIOGRÁFICAS}

[1] DELFORGE DYM, et al. Sinterização de uma mistura de cavaco de aço inoxidável com pó do mesmo material. Uma nova tecnologia para a reciclagem de metais? REM: R. Esc. Minas, Ouro Preto, 60(1): 95-100, jan. mar. 200795.

[2] NEVES MDM. Sinterização de misturas de pós de liga de ferro para aplicações automotivas. Tese de Doutorado - IPEN/USP - 2005.

[3] GERMAN RM. Powder Metallurgy Science, Princeton, N. J. Metal Powder Industries Federation, $1^{\text {st }}$ Ed., 1984.

[4] DeGARMO EP, et al. Materials and Processes in Manufacturing, Upper Saddle River, N.J. Prentice Hall, Eighth Edition, 1997.

[5] SILVA Jr., ITAMAR F, OLIVEIRA VC. A aplicação do controle estatístico de processo numa indústria de beneficiamento de camarão marinho no estado do rio grande do norte Revista Gestão Industrial, 2005.

[6] SILVA ARTHUR PG, et al. O uso do controle estatístico de processos para melhorar o desempenho das empresas de saneamento.

[7] AMARAL DC, ROZENFELD H. Fundamentos de Controle Estatístico de Processo - CEP. IQA, 1997.

[8] GAITHER N, FRAZIER G. Administração da Produção e Operações. São Paulo, Pioneira Thomson Learning, 8ª. Ed., 2001.

[9] MAGALHÃES RR, CYMROT R. Técnicas de monitoramento e controle estatístico de processos através de cartas de controle da soma cumulativa e de cartas de controle de média móvel exponencialmente ponderada X. Encontro Latino Americano de Iniciação Científica e VI Encontro Latino Americano de PósGraduação - Universidade do Vale do Paraíba.

[10] RAMOS AW. Controle estatístico de processo na máquina de papel. Artigo Técnico. Departamento de Engenharia de Produção -Epusp. São Paulo. 2006.

[11] GAITHER N, FRAZIER G. Administração da Produção e Operações. São Paulo, Pioneira Thomson Learning, 8ª. Ed., 2001.

[12] RAMOS AW. CEP para Processos Contínuos e em Bateladas. São Paulo. Edgard Blücher, 2000.

[13] RAMOS AW. Análise Estatística da Qualidade. São Paulo. Departamento de Engenharia de Produção da Escola Politécnica- USP-São Paulo, 2005.

[14] GAITHER N, FRAZIER G. Administração da Produção e Operações. São Paulo, Pioneira Thomson Learning, 8ª . Ed., 2001

[15] AMARAL DC, ROZENFELD H. Fundamentos de controle estatístico de processo - CEP. IQA, 1997.

[16] MOREIRA, D. A. Administração da Produção e Operações. São Paulo, Pioneira. Thomson learning, 2002

[17] ISHIKAWA, K. Controle de Qualidade Total (à maneira japonesa).6 $6^{a}$ Edição. Rio de Janeiro, Editora Campus, 1993.

[18] JURAN, JM. Planejando para a Qualidade. $3^{a}$ Edição. São Paulo, Livraria Editora Pioneira, 1995. 
[19] HARRINGTON, J. Aperfeiçoando Processos Empresariais. São Paulo, Editora McGraw-Hill Ltda. e Makron Books do Brasil Editora Ltda., 1993.

[20] DAVIS, MM.; AQUILANO NJ; CHASE RB. Fundamentos da Administração da Produção. $3^{a}$ Edição. Porto Alegre, Bookman Editora, 2001. 
Anexo 1-3,00 mm

\begin{tabular}{|c|c|c|c|c|c|c|c|c|c|c|c|c|c|c|c|}
\hline \multirow{2}{*}{ Amostras } & \multicolumn{10}{|c|}{ Valores } & \multirow{2}{*}{ Média } & \multicolumn{3}{|c|}{ Amplitude } & \multirow{2}{*}{$\begin{array}{l}\text { Desvio } \\
\text { padrão }\end{array}$} \\
\hline & 1 & 2 & 3 & 4 & 5 & 6 & 7 & 8 & 9 & 10 & & \begin{tabular}{|l|} 
Máximo \\
\end{tabular} & Mínimo & Diferença & \\
\hline $\mathbf{0}$ & 3,059 & 3,050 & 3,062 & 3,048 & 3,049 & 3,049 & 3,049 & 3,043 & 3,057 & 3,062 & 3,053 & 3,062 & 3,043 & 0,019 & 0,007 \\
\hline 1 & 3,060 & 3,056 & 3,059 & 3,047 & 3,047 & 3,040 & 3,057 & 3,051 & 3,055 & 3,048 & 3,052 & 3,060 & 3,040 & 0,020 & 0,006 \\
\hline 2 & 3,056 & 3,047 & 3,051 & 3,049 & 3,067 & 3,057 & 3,049 & 3,052 & 3,039 & 3,068 & 3,053 & 3,068 & 3,039 & 0,029 & 0,009 \\
\hline 3 & 3,053 & 2,974 & 2,971 & 2,981 & 2,976 & 2,976 & 2,996 & 2,998 & 2,969 & 2,977 & 2,987 & 3,053 & 2,969 & 0,084 & 0,025 \\
\hline 4 & 2,983 & 2,975 & 2,983 & 2,993 & 2,984 & 2,978 & 2,974 & 2,975 & 2,984 & 2,968 & 2,980 & 2,993 & 2,968 & 0,025 & 0,007 \\
\hline 5 & 2,989 & 3,021 & 2,995 & 2,983 & 2,992 & 2,977 & 2,970 & 2,976 & 3,010 & 2,960 & 2,987 & 3,021 & 2,960 & 0,061 & 0,018 \\
\hline 6 & 3,022 & 3,017 & 2,999 & 2,991 & 2,984 & 2,991 & 2,980 & 2,971 & 2,986 & 2,989 & 2,993 & 3,022 & 2,971 & 0,050 & 0,016 \\
\hline 7 & 3,000 & 2,983 & 2,994 & 2,990 & 2,987 & 2,984 & 2,986 & 2,977 & 2,988 & 2,987 & 2,988 & 3,000 & 2,977 & 0,023 & 0,006 \\
\hline 8 & 3,039 & 3,026 & 2,997 & 2,986 & 2,987 & 3,000 & 2,980 & 2,993 & 2,979 & 2,981 & 2,997 & 3,039 & 2,979 & 0,060 & 0,020 \\
\hline 9 & 3,024 & 3,007 & 3,003 & 3,005 & 2,997 & 3,003 & 3,013 & 2,989 & 2,996 & 3,004 & 3,004 & 3,024 & 2,989 & 0,035 & 0,010 \\
\hline 10 & 2,992 & 3,011 & 3,004 & 2,995 & 3,019 & 3,018 & 3,026 & 3,001 & 2,994 & 3,015 & 3,007 & 3,026 & 2,992 & 0,034 & 0,012 \\
\hline 11 & 3,024 & 3,008 & 3,034 & 3,001 & 3,015 & 2,997 & 2,981 & 2,978 & 2,997 & 2,991 & 3,002 & 3,034 & 2,978 & 0,056 & 0,018 \\
\hline 12 & 2,981 & 3,005 & 3,029 & 3,009 & 3,006 & 3,001 & 2,999 & 3,017 & 3,005 & 3,011 & 3,006 & 3,029 & 2,981 & 0,048 & 0,012 \\
\hline 13 & 2,996 & 3,005 & 3,003 & \begin{tabular}{|l|}
3,010 \\
\end{tabular} & 3,020 & 2,927 & 3,019 & 3,037 & 3,024 & 3,005 & 3,005 & 3,037 & 2,927 & 0,110 & 0,030 \\
\hline 14 & 3,012 & 3,016 & 2,994 & 3,010 & 3,036 & 3,012 & 3,007 & 3,013 & 3,015 & 3,016 & 3,013 & 3,036 & 2,994 & 0,042 & 0,010 \\
\hline 15 & 3,008 & 3,021 & 3,014 & 3,032 & 3,002 & 3,019 & 3,033 & 3,012 & 3,001 & 3,011 & 3,015 & 3,033 & 3,001 & 0,032 & 0,011 \\
\hline 16 & 3,049 & 3,034 & 3,041 & 3,038 & 3,052 & 3,031 & 3,041 & 3,033 & 3,046 & 3,040 & 3,040 & 3,052 & 3,031 & 0,021 & 0,007 \\
\hline 17 & 3,048 & 3,033 & 3,038 & \begin{tabular}{|l|}
3,037 \\
\end{tabular} & 3,027 & 3,035 & 3,037 & 3,044 & 3,038 & 3,044 & 3,038 & 3,048 & 3,027 & 0,021 & 0,006 \\
\hline 18 & 3,044 & 3,047 & 3,047 & 3,062 & 3,036 & 3,059 & 3,040 & 3,046 & 3,041 & 3,041 & 3,046 & 3,062 & 3,036 & 0,026 & 0,008 \\
\hline 19 & 3,053 & 3,042 & 3,050 & 3,032 & 3,043 & 3,034 & 3,046 & 3,031 & 3,033 & 3,042 & 3,041 & 3,053 & 3,031 & 0,022 & 0,008 \\
\hline 20 & 3,040 & 3,024 & 3,043 & 3,024 & 3,040 & 3,035 & 3,040 & 3,058 & 3,060 & 3,049 & 3,041 & 3,060 & 3,024 & 0,036 & 0,012 \\
\hline 21 & 3,018 & 3,040 & 3,044 & 3,050 & 3,020 & 3,033 & 3,050 & 3,029 & 3,053 & 3,052 & 3,039 & 3,053 & 3,018 & 0,035 & 0,013 \\
\hline 22 & 3,035 & 3,032 & 3,036 & 3,051 & 3,034 & 3,043 & 3,031 & 3,066 & 3,036 & 3,050 & 3,042 & 3,066 & 3,031 & 0,035 & 0,011 \\
\hline 23 & 3,067 & 2,950 & 3,046 & 3,035 & 3,049 & 3,041 & 3,025 & 3,036 & 3,044 & 3,042 & 3,034 & 3,067 & 2,950 & 0,117 & 0,031 \\
\hline 24 & 2,982 & 3,048 & 3,033 & 3,041 & 3,036 & 3,041 & 3,051 & 3,040 & 3,000 & 3,024 & 3,030 & 3,051 & 2,982 & 0,069 & 0,022 \\
\hline 25 & 2,987 & \begin{tabular}{|l|}
3,009 \\
\end{tabular} & 3,015 & 2,997 & 3,014 & 3,000 & 3,074 & 3,065 & 3,071 & 3,030 & 3,026 & 3,074 & 2,987 & 0,087 & 0,032 \\
\hline 26 & 2,975 & 3,001 & 2,991 & \begin{tabular}{|l}
2,999 \\
\end{tabular} & 3,003 & 3,010 & 3,004 & 2,978 & 2,991 & 2,992 & 2,994 & 3,010 & 2,975 & 0,035 & 0,011 \\
\hline 27 & 2,995 & 2,992 & 3,006 & 2,982 & \begin{tabular}{|l|}
2,997 \\
\end{tabular} & 3,079 & 2,973 & 3,006 & 3,074 & 3,064 & 3,017 & 3,079 & 2,973 & 0,105 & 0,040 \\
\hline 28 & 2,988 & 2,983 & 2,977 & 2,979 & 2,982 & 2,988 & 2,981 & 2,984 & 2,991 & 2,987 & 2,984 & 2,991 & 2,977 & 0,015 & 0,005 \\
\hline 29 & 2,968 & 2,979 & 2,993 & 2,987 & 3,003 & 2,994 & 2,987 & 3,055 & 3,061 & 3,066 & 3,009 & 3,066 & 2,968 & 0,098 & 0,037 \\
\hline & & & & & & & & & Xbarr & arra & 3,017 & 3,042 & 2,994 & 0,048 & 0,015 \\
\hline
\end{tabular}


Anexo 2-3,10 mm

\begin{tabular}{|c|c|c|c|c|c|c|c|c|c|c|c|c|c|c|c|}
\hline \multirow{2}{*}{ Amostras } & \multicolumn{10}{|c|}{\begin{tabular}{|l|} 
Valores \\
\end{tabular}} & \multirow{2}{*}{ Média } & \multicolumn{3}{|c|}{ Amplitude } & \multirow{2}{*}{\begin{tabular}{|l} 
Desvio \\
Padrão
\end{tabular}} \\
\hline & 1 & 2 & 3 & 4 & 5 & 6 & 7 & 8 & 9 & 10 & & Máximo & Mínimo & Diferença & \\
\hline 0 & 3,047 & 3,044 & 3,031 & 3,051 & 3,039 & 3,043 & 3,063 & 3,053 & 3,068 & 3,077 & 3,052 & 3,077 & 3,031 & 0,046 & 0,014 \\
\hline 1 & 3,037 & 3,069 & 3,050 & 3,041 & 3,050 & 3,055 & 3,054 & 3,052 & 3,042 & 3,063 & 3,051 & 3,069 & 3,037 & 0,032 & 0,010 \\
\hline 2 & 3,058 & 3,027 & 3,049 & 3,045 & 3,052 & 3,040 & 3,082 & 3,065 & 3,064 & 3,060 & 3,054 & 3,082 & 3,027 & 0,055 & 0,015 \\
\hline 3 & 3,031 & 3,031 & 3,044 & 3,037 & 3,057 & 3,060 & 3,059 & 3,075 & 3,068 & 3,041 & 3,050 & 3,075 & 3,031 & 0,044 & 0,016 \\
\hline 4 & 3,049 & 3,053 & 3,050 & 3,048 & 3,060 & 3,067 & 3,076 & 3,081 & 3,059 & 3,067 & 3,061 & 3,081 & 3,048 & 0,033 & 0,012 \\
\hline 7 & 3,068 & 3,072 & 3,067 & 3,066 & 3,063 & 3,062 & 3,054 & 3,071 & 3,060 & 3,059 & 3,064 & 3,072 & 3,054 & 0,018 & 0,006 \\
\hline 8 & 3,046 & 3,051 & 3,068 & 3,067 & 3,062 & 3,056 & 3,071 & 3,062 & 3,056 & 3,062 & 3,060 & 3,071 & 3,046 & 0,025 & 0,008 \\
\hline 9 & 3,059 & 3,068 & 3,077 & 3,076 & 3,061 & 3,047 & 3,078 & 3,068 & 3,060 & 3,062 & 3,066 & 3,078 & 3,047 & 0,031 & 0,010 \\
\hline 10 & 3,063 & 3,062 & 3,044 & 3,052 & 3,070 & 3,063 & 3,058 & 3,069 & 3,049 & 3,040 & 3,057 & 3,070 & 3,040 & 0,030 & 0,010 \\
\hline 11 & 3,058 & 3,054 & 3,048 & 3,049 & 3,050 & 3,053 & 3,063 & 3,050 & 3,039 & 3,063 & 3,053 & 3,063 & 3,039 & 0,024 & 0,007 \\
\hline 15 & 3,066 & 3,069 & 3,052 & 3,043 & 3,064 & 3,061 & 3,058 & 3,052 & 3,038 & 3,046 & 3,055 & 3,069 & 3,038 & 0,030 & 0,010 \\
\hline 16 & 3,045 & 3,034 & 3,057 & 3,048 & 3,054 & 3,055 & 3,041 & 3,039 & 3,058 & 3,071 & 3,050 & 3,071 & 3,034 & 0,037 & 0,011 \\
\hline 17 & 3,063 & 3,063 & 3,046 & 3,062 & 3,059 & 3,048 & 3,045 & 3,060 & 3,052 & 3,059 & 3,056 & 3,063 & 3,045 & 0,018 & 0,007 \\
\hline 18 & 3,104 & 3,064 & 3,065 & 3,063 & 3,052 & 3,076 & 3,053 & 3,078 & 3,056 & 3,082 & 3,069 & 3,104 & 3,052 & 0,052 & 0,016 \\
\hline 19 & 3,078 & 3,075 & 3,079 & 3,082 & 3,048 & 3,058 & 3,045 & 3,073 & 3,048 & 3,074 & 3,066 & 3,082 & 3,045 & 0,037 & 0,014 \\
\hline 20 & 3,056 & 3,061 & 3,064 & 3,068 & 3,070 & 3,078 & 3,071 & 3,048 & 3,066 & 3,052 & 3,063 & 3,078 & 3,048 & 0,030 & 0,009 \\
\hline 21 & 3,066 & 3,062 & 3,049 & 3,056 & 3,056 & 3,063 & 3,056 & 3,073 & 3,049 & 3,077 & 3,061 & 3,077 & 3,049 & 0,028 & 0,009 \\
\hline 22 & 3,081 & 3,064 & 3,066 & 3,063 & 3,059 & 3,064 & 3,050 & 3,077 & 3,056 & 3,069 & 3,065 & 3,081 & 3,050 & 0,031 & \begin{tabular}{|l|l}
0,009 \\
\end{tabular} \\
\hline 23 & 3,053 & 3,069 & 3,046 & 3,056 & 3,072 & 3,079 & 3,056 & 3,064 & 3,068 & 3,068 & 3,063 & 3,079 & 3,046 & 0,033 & 0,010 \\
\hline 24 & 3,067 & 3,067 & 3,059 & 3,055 & 3,053 & 3,066 & 3,072 & 3,062 & 3,053 & 3,072 & 3,063 & 3,072 & 3,053 & 0,019 & 0,007 \\
\hline 25 & 3,083 & 3,050 & 3,052 & 3,071 & 3,047 & 3,077 & 3,053 & 3,060 & 3,068 & 3,071 & 3,063 & 3,083 & 3,047 & 0,035 & 0,012 \\
\hline
\end{tabular}


Anexo $3-3,20 \mathrm{~mm}$

\begin{tabular}{|c|c|c|c|c|c|c|c|c|c|c|c|c|c|c|c|}
\hline \multirow{2}{*}{ Amostras } & \multicolumn{10}{|c|}{\begin{tabular}{|l|} 
Valores \\
\end{tabular}} & \multirow{2}{*}{ Média } & \multicolumn{3}{|c|}{ Amplitude } & \multirow{2}{*}{$\begin{array}{l}\text { Desvio } \\
\text { Padrão }\end{array}$} \\
\hline & 1 & 2 & 3 & 4 & 5 & 6 & 7 & 8 & 9 & 10 & & Máximo & Mínimo & Diferença & \\
\hline $\mathbf{0}$ & 3,169 & 3,172 & 3,165 & 3,162 & 3,157 & 3,177 & 3,160 & 3,153 & 3,160 & 3,178 & 3,165 & 3,178 & 3,153 & 0,025 & 0,008 \\
\hline 1 & 3,163 & 3,157 & 3,176 & 3,167 & 3,161 & 3,179 & 3,166 & 3,161 & 3,161 & 3,170 & 3,166 & 3,179 & 3,157 & 0,023 & 0,007 \\
\hline 2 & 3,173 & 3,163 & 3,175 & 3,162 & 3,164 & 3,157 & 3,178 & 3,165 & 3,169 & 3,178 & 3,168 & 3,178 & 3,157 & 0,021 & 0,007 \\
\hline 3 & 3,148 & 3,138 & 3,157 & 3,165 & 3,165 & 3,165 & 3,161 & 3,170 & 3,161 & 3,162 & 3,159 & 3,170 & 3,138 & 0,031 & 0,009 \\
\hline 4 & 3,168 & 3,153 & 3,168 & 3,153 & 3,152 & 3,165 & 3,153 & 3,163 & 3,175 & 3,153 & 3,160 & 3,175 & 3,152 & 0,023 & 0,009 \\
\hline 5 & 3,172 & 3,166 & 3,169 & 3,154 & 3,160 & 3,153 & 3,167 & 3,159 & 3,158 & 3,161 & 3,162 & 3,172 & 3,153 & 0,019 & 0,006 \\
\hline 7 & 3,162 & 3,162 & 3,154 & 3,158 & 3,163 & 3,154 & 3,164 & 3,163 & 3,161 & 3,165 & 3,161 & 3,165 & 3,154 & 0,012 & 0,004 \\
\hline 8 & 3,174 & 3,169 & 3,158 & 3,172 & 3,176 & 3,173 & 3,164 & 3,161 & 3,168 & 3,170 & 3,169 & 3,176 & 3,158 & 0,017 & 0,006 \\
\hline 9 & 3,188 & 3,164 & 3,185 & 3,159 & 3,162 & 3,170 & 3,171 & 3,172 & 3,174 & 3,173 & 3,172 & 3,188 & 3,159 & 0,029 & 0,009 \\
\hline 10 & 3,179 & 3,169 & 3,179 & 3,176 & 3,163 & 3,157 & 3,188 & 3,184 & 3,168 & 3,188 & 3,175 & 3,188 & 3,157 & 0,031 & 0,011 \\
\hline 11 & 3,173 & 3,169 & 3,165 & 3,173 & 3,176 & 3,167 & 3,162 & 3,161 & 3,167 & 3,175 & 3,169 & 3,176 & 3,161 & 0,015 & 0,005 \\
\hline 12 & 3,156 & 3,169 & 3,156 & 3,169 & 3,180 & 3,188 & 3,176 & 3,174 & 3,166 & 3,190 & 3,172 & 3,190 & 3,156 & 0,034 & 0,012 \\
\hline 13 & 3,161 & 3,152 & \begin{tabular}{|l|}
3,166 \\
\end{tabular} & 3,164 & 3,159 & 3,172 & 3,169 & 3,168 & 3,174 & \begin{tabular}{|l|}
3,176 \\
\end{tabular} & 3,166 & 3,176 & 3,152 & 0,023 & 0,007 \\
\hline 15 & 3,168 & 3,185 & 3,179 & 3,179 & 3,169 & 3,170 & 3,177 & 3,161 & 3,175 & 3,145 & 3,171 & 3,185 & 3,145 & 0,040 & 0,011 \\
\hline 16 & 3,160 & 3,168 & 3,153 & 3,162 & 3,151 & 3,151 & 3,154 & 3,164 & 3,163 & 3,170 & 3,160 & 3,170 & 3,151 & 0,019 & 0,007 \\
\hline 17 & 3,167 & 3,167 & 3,172 & 3,159 & 3,155 & 3,169 & 3,157 & 3,183 & 3,175 & 3,157 & 3,166 & 3,183 & 3,155 & 0,028 & 0,009 \\
\hline 18 & 3,157 & 3,162 & \begin{tabular}{|l|}
3,164 \\
\end{tabular} & 3,165 & 3,162 & 3,153 & 3,163 & 3,164 & 3,152 & \begin{tabular}{|l|}
3,158 \\
\end{tabular} & 3,160 & 3,165 & 3,152 & 0,013 & 0,005 \\
\hline 19 & \begin{tabular}{|l|l|}
3,184 \\
\end{tabular} & 3,185 & 3,163 & 3,173 & 3,186 & 3,167 & 3,162 & 3,166 & 3,166 & 3,166 & 3,172 & 3,186 & 3,162 & 0,024 & 0,010 \\
\hline 20 & 3,155 & 3,178 & \begin{tabular}{|l|}
3,167 \\
\end{tabular} & 3,175 & 3,172 & 3,178 & 3,186 & 3,161 & 3,168 & \begin{tabular}{|l|}
3,161 \\
\end{tabular} & 3,170 & 3,186 & 3,155 & 0,031 & 0,010 \\
\hline 21 & 3,191 & 3,151 & 3,170 & 3,169 & 3,166 & 3,174 & 3,158 & 3,162 & 3,182 & 3,168 & 3,169 & 3,191 & 3,151 & 0,040 & 0,011 \\
\hline 22 & 3,176 & 3,178 & 3,156 & 3,159 & 3,161 & 3,181 & 3,185 & 3,167 & 3,168 & 3,160 & 3,169 & 3,185 & 3,156 & 0,029 & 0,010 \\
\hline 23 & 3,159 & 3,164 & \begin{tabular}{|l|}
3,178 \\
\end{tabular} & 3,165 & 3,156 & 3,157 & 3,182 & 3,175 & 3,184 & \begin{tabular}{|l|}
3,141 \\
\end{tabular} & 3,166 & 3,184 & 3,141 & 0,042 & 0,013 \\
\hline 24 & 3,169 & 3,174 & 3,169 & 3,169 & 3,160 & 3,163 & 3,172 & 3,175 & 3,163 & 3,172 & 3,169 & 3,175 & 3,160 & 0,015 & 0,005 \\
\hline 25 & 3,165 & 3,181 & 3,175 & 3,161 & 3,160 & 3,158 & 3,172 & 3,163 & 3,175 & 3,159 & 3,167 & 3,181 & 3,158 & 0,023 & 0,008 \\
\hline 26 & 3,153 & 3,175 & \begin{tabular}{|l|}
3,162 \\
\end{tabular} & 3,152 & 3,164 & 3,173 & 3,156 & 3,204 & 3,166 & 3,166 & 3,167 & 3,204 & 3,152 & 0,052 & 0,015 \\
\hline 27 & 3,164 & 3,172 & 3,170 & 3,189 & 3,169 & 3,164 & 3,171 & 3,172 & 3,185 & 3,186 & 3,174 & 3,189 & 3,164 & 0,026 & 0,009 \\
\hline 28 & 3,156 & 3,158 & 3,165 & 3,174 & 3,140 & 3,159 & 3,164 & 3,193 & 3,154 & 3,187 & 3,165 & 3,193 & 3,140 & 0,053 & 0,016 \\
\hline \multirow[t]{2}{*}{29} & 3,177 & 3,165 & 3,171 & 3,178 & 3,162 & 3,188 & 3,154 & 3,183 & 3,177 & 3,170 & 3,172 & 3,188 & 3,154 & 0,033 & 0,010 \\
\hline & & & & & & & & & \multicolumn{2}{|c|}{ Xbarra-barra } & 3,167 & & & 0,027 & 0,009 \\
\hline
\end{tabular}


Anexo 4 - 3,30 mm

\begin{tabular}{|c|c|c|c|c|c|c|c|c|c|c|c|c|c|c|c|}
\hline \multirow{2}{*}{ Amostras } & \multicolumn{10}{|c|}{ Valores } & \multirow{2}{*}{ Média } & \multicolumn{3}{|c|}{ Amplitude } & \multirow{2}{*}{$\begin{array}{l}\text { Desvio } \\
\text { Padrão }\end{array}$} \\
\hline & 1 & 2 & 3 & 4 & 5 & 6 & 7 & 8 & 9 & 10 & & \begin{tabular}{|l|} 
Máximo \\
\end{tabular} & \begin{tabular}{|l|} 
Mínimo \\
\end{tabular} & \begin{tabular}{|l|} 
Diferença \\
\end{tabular} & \\
\hline 0 & 3,306 & 3,329 & 3,338 & 3,330 & 3,334 & 3,331 & 3,344 & 3,314 & 3,320 & 3,312 & 3,326 & 3,344 & 3,306 & 0,038 & 0,012 \\
\hline 1 & 3,325 & 3,329 & 3,328 & 3,324 & 3,323 & 3,322 & 3,344 & 3,327 & 3,328 & 3,318 & 3,327 & 3,344 & 3,318 & 0,026 & 0,007 \\
\hline 2 & 3,326 & 3,339 & 3,325 & 3,336 & 3,327 & 3,326 & 3,314 & 3,317 & 3,309 & 3,323 & 3,324 & 3,339 & 3,309 & 0,030 & 0,009 \\
\hline 3 & 3,310 & 3,329 & 3,319 & 3,319 & 3,326 & 3,328 & 3,314 & 3,325 & 3,332 & 3,328 & 3,323 & 3,332 & 3,310 & 0,022 & 0,007 \\
\hline 4 & 3,326 & 3,330 & 3,318 & 3,322 & 3,315 & 3,312 & 3,344 & 3,336 & 3,325 & 3,333 & 3,326 & 3,344 & 3,312 & 0,032 & 0,010 \\
\hline 5 & 3,315 & 3,328 & 3,307 & 3,310 & 3,315 & 3,306 & 3,331 & 3,305 & 3,302 & 3,313 & 3,313 & 3,331 & 3,302 & 0,029 & 0,009 \\
\hline 6 & 3,306 & 3,307 & 3,314 & 3,309 & 3,308 & 3,302 & 3,309 & 3,298 & 3,307 & 3,309 & 3,307 & 3,314 & 3,298 & 0,016 & 0,004 \\
\hline 7 & 3,310 & 3,319 & 3,309 & 3,290 & 3,320 & 3,314 & 3,318 & 3,305 & 3,307 & 3,302 & 3,309 & 3,320 & 3,290 & 0,031 & 0,009 \\
\hline 8 & 3,299 & 3,308 & 3,324 & 3,318 & 3,313 & 3,307 & 3,305 & 3,298 & 3,292 & 3,294 & 3,306 & 3,324 & 3,292 & 0,032 & 0,010 \\
\hline 9 & 3,304 & 3,306 & 3,306 & 3,320 & 3,317 & 3,304 & 3,310 & 3,327 & 3,328 & 3,322 & 3,314 & 3,328 & 3,304 & 0,024 & 0,010 \\
\hline 10 & 3,321 & 3,312 & 3,335 & 3,327 & 3,333 & 3,324 & 3,322 & 3,315 & 3,313 & 3,314 & 3,321 & 3,335 & 3,312 & 0,023 & 0,008 \\
\hline 11 & 3,326 & 3,309 & 3,319 & 3,325 & 3,329 & 3,320 & 3,329 & 3,336 & 3,335 & 3,311 & 3,324 & 3,336 & 3,309 & 0,026 & 0,009 \\
\hline 12 & 3,321 & 3,329 & 3,334 & 3,329 & 3,332 & 3,335 & 3,340 & 3,336 & 3,322 & 3,326 & 3,330 & 3,340 & 3,321 & 0,018 & 0,006 \\
\hline 13 & 3,322 & 3,325 & 3,328 & 3,347 & 3,317 & 3,322 & 3,327 & 3,339 & 3,340 & 3,307 & 3,328 & 3,347 & 3,307 & 0,040 & 0,012 \\
\hline 14 & 3,307 & 3,336 & 3,325 & 3,317 & 3,302 & 3,358 & 3,327 & 3,346 & 3,348 & 3,335 & 3,330 & 3,358 & 3,302 & 0,056 & 0,018 \\
\hline 15 & 3,323 & 3,326 & 3,354 & 3,313 & 3,348 & 3,326 & 3,351 & 3,352 & 3,332 & 3,343 & 3,337 & 3,354 & 3,313 & 0,042 & 0,015 \\
\hline 16 & 3,318 & 3,320 & 3,312 & 3,316 & 3,311 & 3,330 & 3,329 & 3,325 & 3,331 & 3,338 & 3,323 & 3,338 & 3,311 & 0,027 & 0,009 \\
\hline 17 & 3,349 & 3,344 & 3,337 & 3,341 & 3,311 & 3,300 & 3,291 & 3,298 & 3,308 & 3,312 & 3,319 & 3,349 & \begin{tabular}{|l|l|}
3,291 \\
\end{tabular} & 0,059 & 0,022 \\
\hline 18 & 3,263 & 3,323 & 3,314 & 3,326 & 3,330 & \begin{tabular}{|l|l|}
3,329 \\
\end{tabular} & 3,324 & 3,340 & 3,338 & 3,341 & 3,323 & 3,341 & 3,263 & 0,079 & 0,023 \\
\hline 19 & 3,323 & 3,330 & 3,316 & 3,312 & 3,337 & 3,320 & 3,324 & 3,335 & 3,310 & 3,321 & 3,323 & 3,337 & 3,310 & 0,028 & 0,009 \\
\hline 20 & 3,333 & 3,321 & 3,327 & 3,331 & 3,337 & 3,324 & 3,332 & 3,326 & 3,334 & 3,336 & 3,330 & 3,337 & 3,321 & 0,016 & 0,005 \\
\hline 21 & 3,334 & 3,333 & 3,342 & 3,319 & 3,359 & 3,320 & 3,338 & 3,336 & 3,314 & 3,331 & 3,333 & 3,359 & 3,314 & 0,045 & 0,013 \\
\hline 22 & 3,311 & 3,358 & 3,327 & 3,339 & 3,369 & 3,336 & 3,321 & 3,342 & 3,340 & 3,355 & 3,340 & 3,369 & \begin{tabular}{|l|l|}
3,311 \\
\end{tabular} & 0,059 & 0,018 \\
\hline 23 & 3,334 & 3,352 & 3,334 & 3,352 & 3,367 & 3,342 & 3,353 & 3,336 & 3,352 & 3,351 & 3,347 & 3,367 & 3,334 & 0,033 & 0,011 \\
\hline 24 & 3,343 & 3,352 & 3,355 & 3,357 & 3,359 & 3,354 & 3,349 & 3,346 & \begin{tabular}{|l|l|}
3,359 \\
\end{tabular} & 3,362 & 3,354 & 3,362 & 3,343 & 0,019 & 0,006 \\
\hline 25 & 3,369 & 3,341 & 3,345 & 3,358 & 3,343 & 3,337 & 3,326 & 3,339 & 3,343 & 3,330 & 3,343 & 3,369 & 3,326 & 0,043 & 0,013 \\
\hline 26 & 3,328 & 3,313 & \begin{tabular}{|l|l}
3,324 \\
\end{tabular} & 3,336 & 3,352 & 3,351 & 3,317 & 3,330 & 3,373 & 3,345 & 3,337 & 3,373 & 3,313 & 0,060 & 0,018 \\
\hline 27 & 3,340 & 3,334 & 3,331 & 3,344 & 3,348 & 3,328 & 3,334 & 3,349 & 3,337 & 3,336 & 3,338 & 3,349 & 3,328 & 0,020 & 0,007 \\
\hline 28 & 3,336 & 3,340 & 3,347 & 3,342 & 3,347 & 3,344 & 3,348 & 3,349 & 3,354 & 3,329 & 3,344 & 3,354 & 3,329 & 0,025 & 0,007 \\
\hline 29 & 3,348 & 3,353 & 3,320 & 3,324 & 3,336 & 3,328 & 3,340 & 3,346 & 3,361 & 3,328 & 3,338 & 3,361 & 3,320 & 0,041 & 0,014 \\
\hline & & & & & & & & & |Xbarra & parra & 3,328 & & & 0,035 & 0,011 \\
\hline
\end{tabular}


Anexo 5 - 3,40 mm

\begin{tabular}{|c|c|c|c|c|c|c|c|c|c|c|c|c|c|c|c|}
\hline \multirow{2}{*}{ Amostras } & \multicolumn{10}{|c|}{\begin{tabular}{|l|} 
Valores \\
\end{tabular}} & \multirow{2}{*}{ Média } & \multicolumn{3}{|c|}{ Amplitude } & \multirow{2}{*}{$\begin{array}{l}\text { Desvio } \\
\text { padrão }\end{array}$} \\
\hline & 1 & 2 & 3 & 4 & 5 & 6 & 7 & 8 & 9 & 10 & & Máximo & Mínimo & Diferença & \\
\hline 0 & 3,409 & 3,424 & 3,427 & 3,410 & 3,416 & 3,431 & 3,431 & 3,429 & 3,441 & 3,418 & 3,424 & 3,441 & 3,409 & 0,031 & 0,010 \\
\hline 1 & 3,421 & 3,401 & 3,404 & 3,422 & 3,436 & 3,439 & 3,422 & 3,430 & 3,437 & 3,427 & 3,424 & 3,439 & 3,401 & 0,038 & 0,013 \\
\hline 2 & 3,430 & 3,438 & 3,424 & 3,425 & 3,417 & 3,428 & 3,429 & 3,430 & 3,444 & 3,463 & 3,433 & 3,463 & 3,417 & 0,046 & 0,013 \\
\hline 3 & 3,446 & 3,461 & 3,435 & 3,428 & 3,441 & 3,436 & 3,438 & 3,434 & 3,450 & 3,442 & \begin{tabular}{|l|}
3,441 \\
\end{tabular} & 3,461 & 3,428 & 0,033 & 0,009 \\
\hline 4 & 3,443 & 3,450 & 3,450 & 3,428 & 3,447 & 3,425 & 3,402 & 3,404 & 3,387 & 3,408 & 3,425 & 3,450 & 3,387 & 0,063 & 0,023 \\
\hline 6 & 3,400 & 3,427 & 3,431 & 3,453 & 3,449 & 3,435 & 3,452 & 3,451 & 3,416 & 3,442 & 3,436 & 3,453 & 3,400 & 0,053 & 0,017 \\
\hline 7 & 3,446 & 3,464 & & 3,453 & 3,444 & 3,454 & 3,428 & 3,427 & 3,372 & 3,417 & 3,434 & 3,464 & 3,372 & 0,092 & 0,028 \\
\hline 8 & 3,460 & 3,456 & 3,458 & 3,466 & 3,441 & 3,449 & 3,454 & 3,453 & 3,441 & 3,392 & 3,447 & 3,466 & 3,392 & 0,074 & 0,021 \\
\hline 9 & 3,405 & 3,442 & 3,443 & 3,444 & 3,449 & 3,432 & 3,444 & 3,447 & 3,429 & 3,437 & 3,437 & 3,449 & 3,405 & 0,044 & 0,013 \\
\hline 10 & 3,433 & 3,424 & 3,437 & 3,448 & 3,446 & 3,504 & 3,438 & 3,450 & 3,444 & 3,422 & 3,445 & 3,504 & 3,422 & 0,082 & 0,023 \\
\hline 11 & 3,445 & 3,407 & 3,455 & 3,445 & 3,433 & 3,438 & 3,438 & 3,447 & 3,427 & 3,434 & \begin{tabular}{|l|l}
, 437 \\
\end{tabular} & 3,455 & 3,407 & 0,048 & 0,013 \\
\hline 12 & 3,427 & 3,429 & 3,440 & 3,422 & 3,437 & 3,439 & 3,425 & 3,410 & 3,409 & 3,419 & 3,426 & 3,440 & 3,409 & 0,031 & 0,011 \\
\hline 13 & 3,454 & 3,434 & 3,437 & 3,440 & 3,496 & 3,459 & 3,424 & 3,436 & 3,434 & 3,438 & 3,445 & 3,496 & 3,424 & 0,072 & 0,020 \\
\hline 14 & 3,433 & 3,426 & 3,436 & 3,417 & 3,426 & 3,470 & 3,446 & 3,432 & 3,430 & 3,457 & 3,437 & 3,470 & 3,417 & 0,053 & 0,016 \\
\hline 15 & 3,417 & 3,428 & 3,434 & 3,436 & 3,427 & 3,422 & 3,410 & 3,413 & 3,439 & 3,443 & 3,427 & 3,443 & 3,410 & 0,033 & 0,011 \\
\hline 16 & 3,443 & 3,434 & 3,454 & 3,420 & 3,461 & 3,429 & 3,477 & 3,431 & 3,435 & 3,441 & \begin{tabular}{|l|l}
3,442 \\
\end{tabular} & 3,477 & 3,420 & 0,057 & 0,017 \\
\hline 17 & 3,429 & 3,434 & 3,425 & 3,434 & 3,424 & 3,429 & 3,425 & 3,434 & 3,410 & 3,451 & 3,429 & 3,451 & 3,410 & 0,041 & 0,010 \\
\hline 18 & 3,410 & 3,435 & 3,449 & 3,432 & 3,427 & 3,436 & 3,437 & 3,421 & 3,422 & 3,432 & 3,430 & 3,449 & 3,410 & 0,039 & 0,011 \\
\hline 19 & 3,414 & 3,407 & 3,423 & 3,442 & 3,410 & 3,428 & 3,432 & 3,440 & 3,432 & 3,425 & 3,425 & 3,442 & 3,407 & 0,035 & 0,012 \\
\hline 20 & 3,423 & 3,429 & 3,428 & 3,422 & 3,431 & 3,436 & 3,409 & 3,399 & 3,423 & 3,433 & 3,423 & 3,436 & 3,399 & 0,038 & 0,011 \\
\hline 21 & 3,415 & 3,382 & 3,434 & 3,477 & 3,448 & 3,430 & 3,431 & 3,451 & 3,428 & 3,449 & 3,434 & 3,477 & 3,382 & 0,096 & 0,025 \\
\hline 22 & 3,415 & 3,382 & 3,434 & 3,477 & 3,448 & 3,430 & 3,431 & 3,451 & 3,428 & 3,449 & 3,434 & 3,477 & 3,382 & 0,096 & 0,025 \\
\hline 23 & 3,417 & 3,396 & 3,405 & 3,411 & 3,438 & 3,441 & 3,459 & 3,435 & 3,439 & 3,437 & 3,428 & 3,459 & 3,396 & 0,063 & 0,019 \\
\hline 24 & 3,437 & 3,444 & 3,389 & 3,424 & 3,409 & 3,415 & 3,427 & 3,420 & 3,442 & 3,441 & 3,425 & 3,444 & 3,389 & 0,054 & 0,017 \\
\hline 25 & 3,414 & 3,409 & 3,427 & 3,412 & 3,450 & 3,440 & 3,431 & 3,427 & 3,421 & 3,434 & 3,426 & 3,450 & 3,409 & 0,041 & 0,013 \\
\hline 26 & 3,447 & 3,427 & 3,426 & 3,415 & 3,449 & 3,444 & 3,425 & 3,433 & 3,427 & 3,441 & 3,433 & 3,449 & 3,415 & 0,034 & 0,011 \\
\hline 27 & 3,423 & 3,409 & 3,420 & 3,409 & 3,425 & 3,416 & 3,420 & 3,444 & 3,443 & 3,444 & 3,425 & 3,444 & 3,409 & 0,035 & 0,014 \\
\hline 28 & 3,408 & 3,448 & 3,458 & 3,497 & 3,459 & 3,441 & 3,439 & 3,448 & 3,429 & 3,455 & 3,448 & 3,497 & 3,408 & 0,090 & 0,023 \\
\hline 29 & 3,430 & 3,429 & 3,421 & 3,424 & 3,445 & 3,464 & 3,451 & 3,431 & 3,439 & 3,425 & 3,436 & 3,464 & 3,421 & 0,043 & 0,014 \\
\hline & & & & & & & & & Xbar & arra & 3,433 & & & 0,054 & 0,016 \\
\hline
\end{tabular}


Anexo $6-3,60 \mathrm{~mm}$

\begin{tabular}{|c|c|c|c|c|c|c|c|c|c|c|c|c|c|c|c|}
\hline \multirow{2}{*}{ Amostras } & \multicolumn{10}{|c|}{ Valores } & \multirow{2}{*}{ Média } & \multicolumn{3}{|c|}{ "Amplitude } & \multirow{2}{*}{$\begin{array}{l}\text { Desvio } \\
\text { Padrão }\end{array}$} \\
\hline & 1 & 2 & 3 & 4 & 5 & 6 & 7 & 8 & 9 & 10 & & Máximo & Mínimo & Diferença & \\
\hline $\mathbf{0}$ & 3,616 & 3,614 & 3,613 & 3,617 & 3,614 & 3,624 & 3,624 & 3,610 & 3,635 & 3,628 & 3,619 & 3,635 & 3,610 & 0,025 & 0,008 \\
\hline 1 & 3,616 & 3,620 & 3,624 & 3,605 & 3,612 & 3,611 & 3,620 & 3,615 & 3,624 & 3,603 & 3,615 & 3,624 & 3,603 & 0,021 & 0,007 \\
\hline 2 & 3,621 & & & 3,586 & 3,607 & 3,602 & 3,606 & 3,618 & 3,587 & 3,626 & 3,607 & 3,626 & 3,586 & 0,041 & 0,015 \\
\hline 3 & 3,605 & 3,596 & 3,611 & 3,608 & 3,605 & 3,599 & 3,612 & 3,621 & 3,598 & 3,610 & 3,606 & 3,621 & 3,596 & 0,025 & 0,008 \\
\hline 4 & 3,623 & 3,579 & 3,584 & 3,608 & 3,615 & 3,623 & 3,603 & 3,613 & 3,611 & 3,617 & 3,608 & 3,623 & 3,579 & 0,045 & 0,015 \\
\hline 5 & 3,587 & 3,615 & 3,614 & 3,612 & 3,570 & 3,584 & 3,611 & 3,611 & 3,602 & 3,578 & 3,598 & 3,615 & 3,570 & 0,044 & 0,017 \\
\hline 6 & 3,623 & 3,612 & 3,613 & 3,614 & 3,613 & 3,598 & 3,610 & 3,605 & 3,617 & 3,616 & 3,612 & 3,623 & 3,598 & 0,024 & 0,007 \\
\hline 7 & 3,590 & 3,593 & 3,600 & 3,602 & 3,602 & 3,619 & & & 3,562 & 3,573 & 3,593 & 3,619 & 3,562 & 0,057 & 0,018 \\
\hline 8 & 3,627 & 3,587 & 3,594 & 3,601 & 3,608 & 3,609 & 3,615 & 3,615 & 3,619 & 3,601 & 3,608 & 3,627 & 3,587 & 0,040 & 0,012 \\
\hline 9 & 3,584 & 3,605 & 3,596 & 3,599 & 3,607 & 3,611 & 3,581 & 3,592 & 3,590 & 3,586 & 3,595 & 3,611 & 3,581 & 0,029 & 0,010 \\
\hline 10 & 3,600 & 3,590 & 3,591 & 3,595 & 3,592 & 3,587 & 3,609 & 3,594 & 3,593 & 3,591 & 3,594 & 3,609 & 3,587 & 0,022 & 0,006 \\
\hline 17 & 3,605 & 3,597 & 3,629 & 3,596 & 3,589 & 3,597 & 3,613 & 3,601 & 3,605 & 3,605 & 3,604 & 3,629 & 3,589 & 0,040 & 0,011 \\
\hline 18 & 3,616 & 3,620 & 3,621 & 3,600 & 3,603 & 3,595 & 3,604 & 3,595 & 3,593 & 3,613 & 3,606 & 3,621 & 3,593 & 0,027 & 0,011 \\
\hline 19 & 3,627 & 3,617 & 3,612 & 3,596 & 3,598 & 3,609 & 3,611 & 3,574 & 3,622 & 3,612 & 3,608 & 3,627 & 3,574 & 0,053 & 0,015 \\
\hline 20 & 3,621 & 3,618 & 3,603 & 3,597 & 3,592 & 3,599 & 3,589 & 3,599 & 3,599 & 3,597 & 3,602 & 3,621 & 3,589 & 0,032 & 0,010 \\
\hline 21 & 3,619 & 3,633 & 3,601 & 3,616 & 3,612 & 3,602 & 3,597 & 3,568 & 3,594 & 3,619 & 3,606 & 3,633 & 3,568 & 0,065 & 0,018 \\
\hline 22 & 3,637 & 3,594 & 3,635 & 3,613 & 3,616 & 3,605 & 3,607 & 3,600 & 3,625 & 3,631 & 3,616 & 3,637 & 3,594 & 0,043 & 0,015 \\
\hline 23 & 3,602 & 3,594 & 3,598 & 3,605 & 3,619 & 3,606 & 3,590 & 3,604 & 3,623 & 3,609 & 3,605 & 3,623 & 3,590 & 0,033 & 0,010 \\
\hline 24 & 3,611 & 3,598 & 3,613 & 3,625 & 3,622 & 3,628 & 3,628 & 3,598 & & 3,616 & 3,616 & 3,628 & 3,598 & 0,031 & 0,012 \\
\hline 25 & 3,594 & 3,641 & 3,622 & & 3,627 & 3,621 & 3,626 & 3,627 & \begin{tabular}{|l|}
3,592 \\
\end{tabular} & 3,624 & 3,619 & 3,641 & 3,592 & 0,049 & 0,016 \\
\hline 26 & 3,618 & 3,607 & 3,619 & 3,637 & 3,606 & 3,610 & 3,611 & 3,645 & 3,615 & 3,596 & 3,616 & 3,645 & 3,596 & 0,049 & 0,015 \\
\hline 27 & 3,619 & 3,627 & 3,601 & \begin{tabular}{|l|}
3,579 \\
\end{tabular} & 3,626 & & 3,593 & 3,616 & 3,619 & 3,606 & 3,609 & 3,627 & 3,579 & 0,048 & 0,016 \\
\hline 28 & 3,620 & 3,617 & 3,618 & 3,594 & 3,608 & 3,607 & 3,610 & 3,611 & 3,614 & 3,601 & 3,610 & 3,620 & 3,594 & 0,026 & 0,008 \\
\hline \multirow[t]{2}{*}{29} & & 3,615 & 3,599 & 3,596 & 3,616 & 3,618 & 3,594 & 3,609 & 3,614 & 3,607 & 3,608 & 3,618 & 3,594 & 0,024 & 0,009 \\
\hline & & & & & & & & & \multicolumn{2}{|c|}{ Xbarra-barra } & 3,607 & & & 0,036 & 0,012 \\
\hline
\end{tabular}

